\title{
BEING CANADIAN AND AHMADI MUSLIM: \\ EXPLORING IDENTITY FORMATION OF YOUNG AHMADI WOMEN \\ By
}

Aisha Mohammad, 2018

Bachelor of Child and Youth Care

Humber College 2017

A Major Research Paper

presented to Ryerson University

in partial fulfillment of the requirements for the degree of

Master of Arts

in the program of

Immigration and Settlement Studies

Toronto, Ontario, Canada 2018

(C)Aisha Mohammad, 2018 


\section{Author's Declaration}

I hereby declare that I am the sole author of this major research paper.

I authorize Ryerson University to lend this MRP to other institutions or individuals for the purpose of scholarly research.

I further authorize Ryerson University to reproduce this MRP by photocopying or by

other means, in total or in part, at the request of other institutions or individuals for the purpose of scholarly research.

I understand that my MRP may be made electronically available to the public.

Aisha Mohammad 


\title{
Being Canadian And Ahmadi Muslim:
}

Exploring identity Formation of young Ahmadi Muslim women

\author{
(C)Aisha Mohammad \\ Master of Arts 2018 \\ Immigration and Settlement Studies \\ Ryerson University
}

\begin{abstract}
This study explored the identity formation of young women from a minority Muslim group known as Ahmadis in Canada. Nine unstructured interviews were conducted with women between the ages of 20-26. The questions that this study explored were: How do Ahmadi Muslim women understand and negotiate their identities? What are the factors that shaped and influenced their identity? The participants noted various components of Canadian and Ahmadi identity. Being Canadian meant having multiculturalism/ diversity, being accepting, polite, watching hockey and eating foods such as poutine. Being Ahmadi Muslim meant to have a strong sense of community (Jama 'at), a sense of sisterhood and unity. The study also found various factors which shaped the identities of these young women which included family, friends, location, the Jama 'at (community) and parent's immigration history. Recommendations for theory and practice are provided as well as implications for future research.
\end{abstract}

Key Words: Identity, Ahmadi Muslim women, Identity formation, Canadian 


\section{Acknowledgements}

I would like to acknowledge a few people who have made this research and MRP possible.

First, I would like to thank Allah Almighty for always helping me stay strong and helping me get through the program and MRP.

I would like to extend a special thanks to my supervisor Dr. Mehrunnisa Ali who worked very closely with me and provided supervision, guidance and wisdom every step of the way. This would not have been possible without her.

I would also like to thank Dr.Sedef Arat-Koç for serving as my second reader and providing me with her guidance and precious time.

This research would also have been impossible without the nine young Ahmadi women who participated in my research and provided me with valuable experiences and knowledge.

Lastly, I would like to thank all my professors who have taught me throughout the program, my peers and my family, especially my twin sister Sunbal for her support and feedback and my best friend Fatima Cheema for her ongoing support. 
Table of Contents

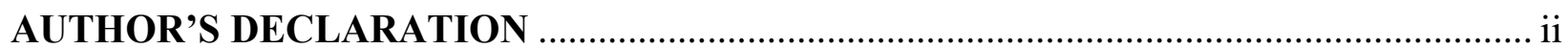

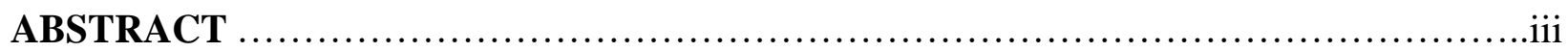

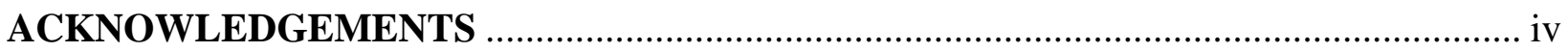

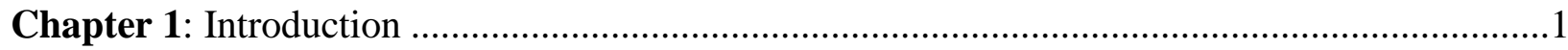

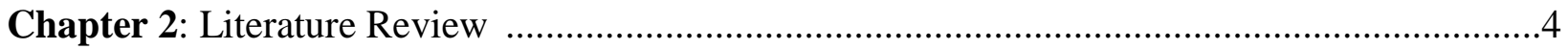

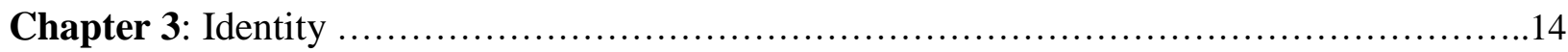

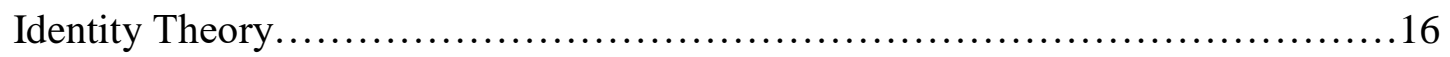

Chapter 4: History of Muslims and Ahmadi Muslims...................................18

Ahmadi Muslims......................................................20

Ahmadis in Canada.........................................................23

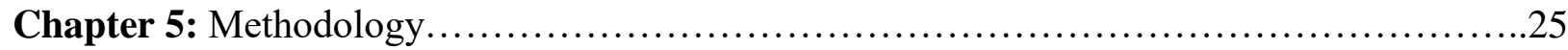

Self-disclosure..................................................... 25

Participants........................................................ 30

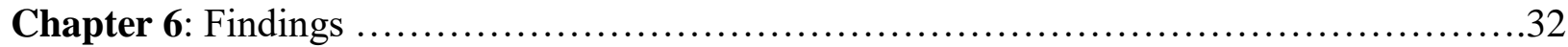

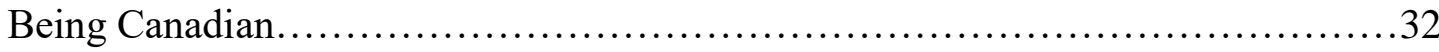

Being Ahmadi Muslim.................................................. 38

Being Canadian and Ahmadi Muslim ........................................41

Factors influencing identity formation...................................46

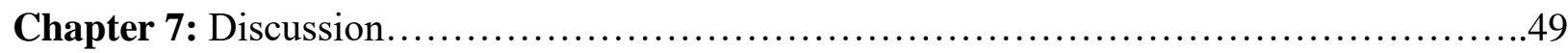

Chapter 8: Conclusion ....................................................... 56

References........................................................ 58

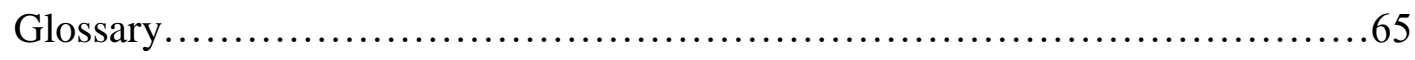


You can walk outside and in five minutes you can see someone from every race....no one is actually truly "Canadian" ....very few people are truly "Canadian" ...if you know what I mean (Laughs). Their ancestors are like from here like or they're like Indigenous people .... well like there are Indigenous people here but like majority of the people you meet in your life here, will not be (Naima: Participant, Brampton ON).

\section{Chapter 1: Introduction}

Canada as a multicultural country is home to many different cultures, ethnicities and religions from around the world. Canada welcomes immigrants with different beliefs and identities. However, even in this multicultural society, some immigrant groups are still othered and may face discrimination. Interestingly, Hamdon (2010) finds that while it is not uncommon for immigrants to feel out of place, "what is unusual is that Muslims have been in Canada for over 100 years and are still struggling to find their place” (p.39). As Zine (2001) for example, suggests that Muslim students in the public education system feel they have to choose between their Islamic identity and their peer groups in schools. This may be because of the differences in the value system of Islam and Canadian values. For example, "things such as dating and premarital sex, drug and alcohol use, which are common practices among many youth in North America, are strictly forbidden in Islam" (Zine, 2001, p. 399). Further, Muslim women who cover themselves with the hijab or niqab are often viewed as oppressed whereas Canadian values encourage women to proudly display their bodies if they wish to. As Bakht (2008) mentions "the most commonly heard opposition to the veil is that women cover their faces or heads at the command of men, so that the veil is seen as a sign of Muslim women's oppression, as well as a general indicator of the "backwardness" of Islamic culture" (p. 106). The widely held misconception is that all Muslim women who wear the veil or niqab are forced to do so. 
The cultural differences between Muslims and others living in Canada are highlighted in the media, often by using sensational cases. For example, in 2010 there was a case of an honor killing of a Pakistani Muslim girl in Mississauga.

"The case which became the talk of national and international media including broadcast heavyweights CNN and BBC, is a heartbreaking dark side of Mississauga's multiculturalism ..... a 16-year-old high school student strangled to death in her Longhorn Trail home, the victim of the collision of two cultural worlds: the restrictive one her Pakistani parents prescribed for her and the westernized, liberal one she tried to choose for herself" (Rosella, 2017, para 7).

While this is clearly an extreme case of perceived cultural collision, it is often assumed that other young Muslim women living in Canada may also be struggling to navigate the two different value systems which they encounter in their everyday lives. Beyer and Ramji (2013) note in their study of Muslim women, that many of them had to negotiate between cultural and religious values, which frequently overlapped, and in both situations, they often found themselves in the position of representing not only themselves but their families, faith, and communities This meant that the participants actions were judged not only individually but as a group. Further, Litchmore and Safdar (2014) found that Muslim women face greater discrimination on the basis of religion and ethnicity than Muslim men, possibly because some of them wear the hijab, which visibly marks their religious and/or cultural identity. Yousif (2007) claims that "[o]thers who try to adapt to the new society's values and culture find themselves trying to avoid being conspicuous in any way. Personal discrimination has few boundaries, and in institutional form, it often leads to a conflict of identity" (p. 20).

Even young Muslim women who were born and raised in Canada may be discriminated against and not seen as fully Canadian because of the widespread belief that Muslim women are different from Canadian women, commonly understood as White women of European origins. 
Muslim Canadian women therefore may find it difficult to develop a stable identity, which in turn may lead to lack of self-esteem.

It is important to note that identities are not created in a vacuum. Families, communities, neighbourhoods, educational institutions or work-places, and all major institutions in towns and cities and nation-states contribute to the creation and reproduction of identities. Institutional structures and cultures, as well as influential individuals help to shape ascribed and claimed identities in various contexts.

It is also imperative to note that Muslims are not a homogenous group. There are many differences between the sects, ethnicities, and cultures that exist within the Muslim population. Therefore, it is crucial to recognize these differences when addressing Muslims in the literature and the media. This study will focus on the identity formation of young Canadian Ahmadi women who belong to a minority Muslim group in the GTA and surrounding areas. This paper will be using the term 'woman' and girl interchangeably as the literature uses both girls and woman.

The current study will help to investigate how young Ahmadi Muslim women define their identities and what contributes to the formation of their identities. The specific questions that this study aim to explore are: 1) How do Ahmadi Muslim women understand and negotiate their identity? and 2) What are the factors that shape and influence their identity formation? This study can potentially contribute to the literature as it will provide insight on how young Muslim women, who belong to a minority Muslim sect, understand and negotiate their identities, which could be similar or different to those of majority Muslims in Canada. Ahmadi Muslims are a minority group often not included in research studies. Likewise, the voices of young people often 
neglected in the literature on minority groups will be represented as voices of young Canadian Muslims are often not represented in the public discourse (Wong et al, 2017)

\section{Chapter 2: Literature Review}

There has been growing literature on Muslims and their identity, belonging, discrimination, the hijab and veil in Canada and the western world, specifically in the post 9/11 era. Many authors have explored the Hijab in relation to Islamophobia, identity, and gender construction (Kassam, A. 2007, Litchmore, R. V. H., \& Safdar, S, 2016, Zine, J. 2006). There is also research on the concept of identity and how Muslim youth negotiate their identities both in Ontario and other provinces such as Quebec (Beyer et al, 2013; Tiflati, 2017) Muslims are often questioned on their "Canadian-ness" and ability to adapt to Western norms, it is interesting to see how Muslims themselves identify in terms of being Canadian and Muslim. As mentioned above, Muslims are not a homogenous group and thus can have very different interpretations of being a Muslim depending on the sect, culture, ethnicity and race they belong to. For example, in one study some of the young women acknowledged obedience and respect towards their parents as an important component of their Muslim identity (Wong et al, 2017). Another study found that women's understanding of being Muslim was a private matter and that "it is the private prayer that connects them to Allah and allows them to self-identify as Muslims" (Hussain, 2004, p. 369). Because Islam has many different sects there can be many different understandings of Islam and how Muslims understand themselves. The way Islam is interpreted also changes depending on the country/region, historical period, rural/urban differences and social class. These factors all contribute to a different interpretation of Islam and how it is practiced. Moreover, practicing Islam in a Western society also changes the way it is practiced and understood among young Muslims who are raised in that society. For Canadian Muslims, their 
interpretation of Islam may become what some call "a Canadianized Islam" which means they incorporate some Islamic teachings into their lives, but do not necessarily follow the traditional Islam their parents brought with them from their home countries (Beyer et al, 2013). This also happens because many young people claim that the Islam their parents' practice is often mingled with their culture and thus is not the 'pure' Islam. Thus, young Muslims take it upon themselves to practice what they conceptualize as Islam in its purest form, without mixing in their parents' culture. As one participant in a study from Beyer et al (2013) stated: "in Egypt everyone is assumed to be Muslim. Although many do not follow the teachings of Islam (because they drink and go to bars). It is a cultural definition" (p. 115). This individual wanted to practice Islam based on religious teachings, not the culturally specific form their parents had lived with. Further, Beyer et al. (2013) also found that Muslim women noted "at the same time, none of these women considered their own level of belief and practice of Islam as exceeding that of their parents; they just considered their Islam to be "purer", because it did away with the cultural attachments" (p. 121). Just because these women practiced Islam differently, did not make them more religious than their parents because they just made sure all the cultural teachings were separated from religious teachings. Thus, by purer these women refer to the core teachings of the religion without any cultural influence. However, Muslim women identified higher levels of religious identity than men in most instances (Beyer et al, 2013). Nonetheless, one important aspect of being a Muslim regardless of the sect or culture were the basics of Islam which included fasting, praying five times a day, the five pillars of Islam, sexual discipline, dietary restrictions, core teachings of Sunnah and Quran and wearing a Hijab (Moghissi et al 2009; Yousuf, 2008, Beyer et al, 2013). 
Many young people often struggle to define what it is to be Canadian because being Canadian is not a definitive identity which has clear boundaries. Interestingly, in a 2013 national survey, a majority of Canadians replied that the Charter is the single most important symbol of our national identity (Ahmad, 2017). Many Muslims who live in Canada are very proud to be Canadian and embrace its diversity. In fact, statistics show that "Muslim Canadians report a very high level of patriotism, with 83 percent saying they are very proud to be Canadian (with most of the remainder indicating they are somewhat proud), whereas only 73 percent of non-Muslim Canadians felt very proud of their country" (Environics Institute, "Survey of Muslims in Canada, 2017). Even though Muslims may not be perceived as Canadians, many consider themselves Canadians. As one Muslim, Yusuf notes, "most of us are pretty much aware of the Canadian scene and consider ourselves Canadians before we're Arab or Pakistani” (Hamdon, 2010, p. 39). Even young people with multiple dimensions to their identity such as Arab and Canadian, prioritize their Canadian identities. Further, Hicham Tiflati (2017) conducted a similar qualitative study in Quebec with Sunnis, (sect of Islam) of eleven Muslim youth. He used semistructured interviews to explore the sense of belonging to a religion, a culture, a society and a nation. The specific questions that he attempted to answer were, 1) How do young Muslims understand and define their identity as Canadian Muslims, and 2) How do they negotiate their Muslimness alongside their Quebecois/Quebecoisie identity and/or their Canadianness. The author interviewed both males and females from ages eighteen to twenty-two. The author found that the youth did not separate being Canadian from being Quebecois. Further, the youth were appreciative of their national identity. However, female participants found it harder to be 'hijabis' in Quebec rather than just Muslim. In other words, Muslims girls felt that wearing the Hijab made their religious identity very visible. His research makes an important contribution to 
the literature as it provided insight into both being Muslim in Canada and specifically in Quebec which has a distinct culture compared to the rest of Canada

The literature showed that young Muslims have strong associations with being Canadian and are proud of their Canadian identities whether they live in Ontario or Quebec. Further, many defined Canadianness as being multicultural and accepting/ open to different cultures and religions. They appreciated Canada for allowing people to practice their religion (Tiflati, 2017; Beyer et al, 2013; Hussain, 2004). Nonetheless, young Muslims still face discrimination in Canada, which can often be attributed to Islamophobia. Islamophobia can be defined as "the dread, hatred, and hostility towards Islam and Muslims perpetrated by a series of closed views that imply and attribute negative and derogatory stereotypes and beliefs to Muslims and...which results in practices of exclusion and discrimination" (Kalin, 2011, p. 8). Islamophobia is aimed at both men and women, but Muslim women are targeted more often due to the hypervisibility of the Hijab. Interestingly, both immigrants and Muslim women born and raised in Canada are often discriminated against and not seen as Canadian. Discrimination post 9/11 has affected many Muslims across Canada. As Hamdon (2010) states, "Muslims living in Canada are struggling to make sense of their identities, to come to term with differences within their community(ies), while at the same time attempting to interrupt oppressive discourses which have constructed Muslims as alien, and even dangerous, to the West” (p. 12). Moreover, discrimination can occur in various forms such as employment, everyday interactions and in relationships.

Nagra (2011) conducted a study with 30 young Muslim men and women, in which 14 responded they had faced discrimination and 87 percent had family members or close friends who had faced discrimination. Interestingly, only six women in this study wore the Hijab and 
thus even the non-visible Muslims faced discrimination. Additionally, participants in this study had noted that not only had strangers discriminated against them but also some friends who had started making hurtful jokes about them. Likewise, a study conducted by Zine (2001) showed examples of discrimination within the education system. She conducted an ethnographic analysis of Muslim youth's schooling experiences in Canada, who were committed to maintaining an Islamic lifestyle despite the social pressures of conformity to the dominant culture. Her focus was on how religious identification is connected to other forms of oppression, such as those based on race and gender, and how this affects the schooling experiences of Muslim youth as they struggle to maintain their Islamic identities. The author found various factors identified by her interviewees as having influence on their religious identity, or as challenging their identity, such as peer pressure (positive and negative), gender, race, discrimination and negative perceptions. Further, many students identified differences in treatment by teachers and the schooling system like being placed in ESL class even if their first language was English. This study is quite valuable as it provides detailed accounts of experiences from a small group of students and their parents.

Adding to the literature on discrimination, Litchmore and Safdar (2014) conducted a quantitative study to investigate perceptions of discrimination among Muslim-Canadians and to determine whether these perceptions were related to levels of religiosity, ethnic identity, and gender. The authors conducted surveys with seventy-seven students aged eighteen to twenty-nine who self-identified as Muslim in Ontario. The main question that the authors were trying to answer was "to what extent do first- and second-generation Muslim-Canadians perceive discrimination against their ethnic and religious groups and against themselves as individuals? Further, there were four hypotheses and the ones related to religion were 1) both first- and 
second-generation participants would perceive less discrimination against themselves than against their ethnic and religious groups 2) due to the contrast between the religious practices and belief systems of Islam and the values of Western society, Muslim-Canadians with greater religiosity would perceive greater levels of discrimination against their religious group and against themselves and 3) Muslim women as compared to Muslim men would perceive greater levels of discrimination against their religious group and against themselves. The authors found that there were moderate levels of perceived discrimination and a positive relationship was found between religiosity and perceptions of discrimination. Lastly, perceived discrimination was higher for women than men. Additionally, Beyer and Ramji (2013) conducted a large study on the notion of religious identities on 200 Muslim, Buddhist, and Hindu men and women between the ages of 18 and 27. This was a comparative study of immigrant families in Canada belonging to three different religions. Majority of the participants were women and Muslims, accounting for almost half of the sample. The aim of this research was to look at the core issue of religious (re) construction in the context of transnational migration. Specifically, 58 Muslim women participated in the interviews to share what it meant to be a Muslim in Canada. The women expressed a stronger individual religious identity rather than having a strong association with their religious communities: "Their religious identities were not shaped or nurtured primarily or all that directly by their religious communities, but a significant number of the most highly involved youths considered themselves deeply religious" (Beyer et al, 2013, p. 120). Further, for Muslim women it was found that "many expressed an inner struggle to balance their lives as Muslims and Canadians: to maintain a Muslim identity while at the same time fully participating in Canadian culture" ( $p$ 113-114). The Muslims in this study had different levels of religiosity, but many practiced Islam at an individual level, rather than at a community level. 
The above literature demonstrates the different levels of discrimination Muslims face, from hurtful jokes to serious events such as physical harassment and verbal assaults. Other forms of discrimination included not being able to find jobs because of associations with certain Muslim communities such as student group at universities which were mentioned on resumes. Muslims in Canada continue to face discrimination at different levels, some which may not always seem serious to 'very serious' acts of discrimination. However, discrimination of any kind can impact young people negatively, especially those who belong to a minority group and are already marginalized and othered by society.

Another aspect of Muslim identity which is often discussed is the importance of the Hijab. The Hijab is an Islamic head covering that Muslim women wear to cover their hair and bosom. The Hijab can be an essential part of a Muslim woman's life and it is difficult to discuss the identity of Muslim women without mentioning the hijab as it is quite often the most visible marker of Muslim identity, though not all Muslim women wear the Hijab. According to Mohammadi (2018), "Studying the Hijab and the veil is important since from a historical perspective the dress code of Muslim women has become a central symbol of their identities and a major component of discussions and debates on modernity and tradition" (p. 6). Further, the Hijab has long been seen as a sign of oppression, backwardness or in violation of women's rights in the Western world. For example, in Quebec there have been instances of girls being kicked out from school because they wore the Hijab. The literature showed that the Hijab had a big influence on 'Muslim identity'. For example, Lictchmore and Safdar (2016) conducted a study with Muslim women who wore the Hijab and did not wear the Hijab and found that "the headscarf can be a strong marker of Muslim identity" (p. 204). Additionally, as found in a study in Quebec, girls who wore the Hijab felt that they were very visibly Muslim. Interestingly, when 
the female participants in the study were asked about the difficulty of being a Muslim in Canada, one responded by asking if he meant "do you mean Muslim or hijabi? This demonstrates an interesting finding that being Muslim can be different from being a "Hijabi" (p. 11), because it visually identifies someone as a Muslim. However, without a Hijab, many Muslim women become disassociated from Islam for the general Canadian society because they cannot tell if they are Muslim by looking at them. "In the context of Canadian female Muslims, research data shows that women who do not wear the Hijab feel more integrated into society and more Canadian” (Meshal, 2003, p. 96), implying that Muslim who wear the Hijab may not be identified as Canadian simply because they wear the Hijab. This is true for both how Muslims perceive themselves and how other Canadians perceived them. One interesting aspect of the Hijab was that the women who wore the Hijab had done so as a personal choice. Contrary to media depictions of Muslim women being forced to veil, the women in various studies indicated that wearing the Hijab was their personal choice. Eid (2014) noted a participant in his study who claimed: "I'm the one who chose to wear the veil. Like, it's not my parents who're forcing me to do it. No, I just feel it's an obligation. The only thing our parents do is tell us what wearing the veil is all about. They teach us our religion and that's it. And we go: 'OK, now I understand!', and then we wear it" (p.1907).

The above findings represent a contradiction between the reality for Muslim women in Canada and what non-Muslims understand about veiling. Media coverage of the one girl in the entire country who was forced to veil is presented as representative of every Muslim woman's life in Canada (Rosella, 2017). It is also important to note that all studies included both women who wore the Hijab and those who did not wear the Hijab, which indicates a true representation of how Muslim woman actually present themselves in Canada. This demonstrates that not all 
Muslim women who are religious wear the Hijab, and not all women who wear the Hijab are forced to do.

Although there is no specific academic literature on the identity of Ahmadi girls or women in Canada, there is a significant amount of institutional knowledge available about the Ahmadi Muslim community and their belief system through community resources. The Ahmadi community has various websites, books, magazines and radio shows for educational purposes which are very helpful in establishing a foundation. There are also articles written on the ongoing persecution of Ahmadi Muslims in Pakistan.

While there is no academic literature on Ahmadi Muslims in Canada, there are some studies in the U.S., such as Ahmed- Ghosh's (2004) work, that look at how South Asian Ahmadi women in Southern California express their agency through their religious activities in the diaspora. Ahmed-Ghosh also discusses their individual and collective identities throughout her paper. She has been doing research with these women for the past four years which included both interviews and attending their religious meetings and visiting different households to experience their religious activities. She conducted six detailed interviews with the women about topics such as family and its relation to faith and claims that the women considered raising their family as a part of their religious duties. Ahmed-Ghosh's work is valuable because she provides useful information about the Ahmadi community that migrated from South Asia to North America. However, her research lacks the voices of young people as her studies only pertain to older women, specifically who are married. Nonetheless, it made an important contribution to the literature on Ahmadi Muslims which are a minority group that is underrepresented in the literature on Muslims. Finally, a study in England by Moulin (2015) looked at the Ahmadi Muslim community in comparison to other minority groups from other religions such as 
Christianity and Judaism. Its purpose was to explore religious adolescents' experiences in secondary schooling. Many participants reported prejudice and criticism of their beliefs or religious affiliations from their peers and occasionally from teachers. They also perceived their religious traditions to be distorted, imprecisely or unfairly characterized in some lessons. In this study, Ahmadi Muslims are identified as being a minority within England because they were Muslims, and also a minority within the Muslim community. He suggests that it became harder to be an Ahmadi Muslim rather than just a Muslim. This further shows the problems that minority groups can face as they are dealing with the larger dominant society, and their own community which does not accept them. It sheds light on the problems that young people face with their religious identity. Moulin claimed that "the experiences of Ahmadis show the difficulties of both belonging to a visible and stigmatized Muslim minority, but also a minority within that minority. In these circumstances, identity masking became an appropriate strategy for participants" (p. 499).

My research will build on the above findings by trying to fill some of the research gaps by focusing specifically on young Muslim women as the literature demonstrates they are discriminated against more than men. I will be focusing specifically on a minority sect of Islam known as Ahmadis as there is a lack of research on this group. This group is often categorized as a part of mainstream Muslims in the literature even though they are discriminated by the general Muslim population. As Ahmed-Ghosh (2004) on her research of Ahmadis in America states that "while a number of studies on Muslims in North America have been conducted...some minority Muslim communities have not received adequate attention; the Ahmadiyya community is one of these" (p. 73). There have been some studies or books which briefly mention the Ahmadis but never go into detail about the religious group. In comparison, there is a large coverage of the 
Sunnis and some Shia' minorities such as the Ismailis. The next section will discuss the multiple and complex notions of identity and their implications.

\section{Chapter 3: Identity}

Identity is an important concept, which becomes particularly salient during adolescence and early adulthood. This is especially true for young women who are trying to live up to the expectations of families, peers, communities, and society. Questions about identity have come up numerous times in psychology, sociology and literature but there is still no definitive answer about what it is, as identity is a complex phenomenon. Identity does not present itself as a single concept. Rather, many argue that identity cannot be defined in one concrete way and must include different components. Further, there are different types of identities such as ethnic, religious, group or social and personal or micro level identities. The focus of this research is on micro level identities or personal identities of individuals, which includes internal and external identities. Personal identity refers to identity that is associated with how individuals define themselves, name the communities they feel attached to, and how they deal with multiple allegiances and contradictory feelings (Mendelson, 2007).

According to Erikson (1980), internal identity depends on upon the accomplishment of a sense of integration, which starts from a feeling of security, autonomy, and comfort. Externally, identity relates to the social and cultural world in which the individual seeks acceptance. Erik Erikson is believed to be one of the pioneers in the field of identity and identity development. According to Erikson, identity refers to a "a well-organized conception of the self that defines who one is, what one values, and what directions one wants to pursue in life" (Berk, 2012, p. 600). As one of the pioneers in this work, Erik Erikson did a lot of work on identity and identity development. He proposed different stages of identity associated with different roles and 
achievements. For example, his model includes the stage of role confusion which is associated with adolescence. In this stage he discusses the psychological conflict that adolescence go through where they experiment and decide on different values and goals (Berk, 2012).

Since Erikson's work, the concept of identity has further evolved. Many scholars have presented their own ideas about the different aspects of identity, especially for immigrant populations growing up in another country. For example, the idea of hybridized identities has surfaced when speaking about people living in different cultures. Identities can also be conflicting when there is a clash between cultures because the values are not the same and thus causes a constant negotiation between two realities. Khan (1998) calls people experiencing this "hybridized individuals, caught in the discontinuous time of translation and negotiation, erasing any claims for inherent cultural purity, inhabit the rim of an "in-between reality" marked by shifting psychic, cultural, and territorial boundaries" (p. 464). Identity for young people who are a part of more than one culture or society can then become conflicted because they may want to incorporate aspects of both cultures which may not always be possible. However, religious identity can be very different for members of the same religious groups, as there is much diversity even within a religion. Individuals in the same location may define, construct and practice the same religion in a different way (Bectovic, 2011; Beyer et al, 2013).

It is important to remember that identity is intersectional especially in societies like Canada where people of different culture, religions and ethnicities co-exist. A great example of this can be seen in a young person who in describing his identity said:

"The best approach is to say what Tariq Ramadan answered when he was asked that question you know [...] so I will just go along the same lines, basically I am Muslim by religion, Canadian by nationality, Arab by culture, and so on and so forth; I mean 21 st century Man is really a melting pot of different identities. You are no longer just either this 
or that; your identity is defined through many different channels.-Ismail, research participant" (Tiflati, 2017, p. 1)

This person identifies the different components which make up his identity which included his religion, his culture and his nationality. This demonstrates the intersectionality of identity which often includes gender, class and religion/ethnicity/culture. He explains how difficult it is to just label yourself with one identity without leaving out important aspects of yourself. Thus, identity can be understood in various ways and the different aspects of identity can vary from person to person.

Like other concepts, identity theory emerged from various perspectives and disciplines. These include symbolic interactionism, which relates to how people distinguish from or show affiliations with other social units, and perceptual control theory which offers an understanding of purpose and goals of all living things. (Burke and Stets, 2009).

There are various other approaches which try to understand the notion of identity. For example, Jane Kroger (2007) mentions five different approaches: i.e. historical, socio-cultural, narrative, structural and psychosocial approach, which all offer different explanations and influences on identity and identity formation. The historical approach recognizes historical relativity of concern with identity. The sociocultural approach addresses how identities are formed, inhibited, and defined by context. Within this approach Mead (1934) "proposed that people define themselves according to how they perceive others responding to them" (Kroger, 2007, p. 19). Expanding on Mead's ideas, Cote (1996) states that "for many sociologists there is no identity without society, and society steers identity formation while individuals attempt to navigate the passage" (pg. 133). Additionally, the structural approach recognizes developmental 
structures in filtering life events. The narrative approach concentrates on the whole person and how identity elements are combined via one's life story. Lastly, the psychosocial approach addresses the biological, psychological, and societal influences on identity.

In this study I will be using social identity theory which focuses on people's associations or membership with a certain group who share common ideas (Hogg and Abrams, 1988). This is similar to Mead's work in which people define themselves according to how others perceive them because in social groups people evaluate the in group and outgroup. As described by Burke and Stets, "a social group is a set of individuals who share the view that they are members of the same social category. Through a social comparison and categorization process, persons who are similar to the self are categorized with the self and labelled the ingroup" (Burke et al, 2009, p. 118). However, I agree with Burke and Stets who recognize that a "complete theory of the self would consider both the role and the group bases of identity as well as identities based in the person that provide stability across groups, roles, and situations" (2000, p. 234). They claim that they see significant parallels and overlap between social identity theory and identity theory. This overlap eventually will cause these theories to be linked in essential ways (Stets and Burke, 2000). Ultimately, they outline three main similarities between identity and social theory which are the different bases of identity in the two theories, but I will only focus on two specific ones which are relevant to personal and group identities. Firstly, categories or groups for social identity theory, and roles for identity theory. Groups for social identity theory refer to the different groups and communities people associate themselves with. Similarly, in identity theory people have different roles depending on the context. A related issue is the place of personal identities. The second part is the activation of identities and the idea of salience as used in each of the theories. (Stets et al, 2000). I will use their understanding of both theories to demonstrate 
that identities cannot be defined by one dimension, especially individuals who belong to a minority group.

The next section will provide a history of Muslims and Ahmadi Muslims in Canada. I will also provide a background for the Ahmadiyya Muslim Jama 'at.

\section{Chapter 4: Muslims and Ahmadi Muslims}

Although Muslims are a minority in Canada, they have been living here for a very long time. Waugh and colleagues (1983) found that "the earliest record of Muslim presence in Canada dates back to 1871, when the Canadian census recorded 13 Muslim residents" (Waugh, AbuLaban, and Qureshi, 1983, p.76). It is also important to remember that Muslims are not a homogenous group. They come from all over the world with different cultures and speak various languages. As Yousuf states "Muslims in Canada have immigrated from Iraq, Lebanon, Egypt, Palestine, Syria, Morocco, Tunisia, Algeria, the Gulf states. Somalia, Iran, Pakistan, India, Afghanistan, Turkey, Bosnia, Africa, Eastern Europe, the Caribbean and Central America” (Yousif, 2008, p. 14). The first Muslim family which settled in Canada was from Scotland (Hamdani, 2015). As Hamdani writes, "from the pioneers in pre-Confederation Canada to the labourers who toiled on the physical infrastructure, to the farmers who settled the prairies in the twentieth century -- Muslims have been partners in the task of nation building" (Hamdani, 2015, p.1). In terms of institutional establishments, the first mosque was built in Edmonton Alberta in 1938 and was called Al-Rashid (Yousif, 2008). Currently, Muslims make up the second largest religious groups in Canada with over a million people which represented 3.2\% of the nation's population (Stats Canada, 2016). A survey conducted in 2007 found that the mean age of Muslims in Canada is 36.8 years compared to 46.9 years for the general population, and that 
Canadian Muslims, both male and female, are more likely than the overall population to have completed one or more university degree (Riley, 2011).

Muslim women in Canada are mostly immigrants from Africa, Asia, China and Arabia. Surprisingly, Muslim women tend to be more educated than regular Canadian women. "Overall, these figures show that Muslim women form part of a highly educated, professional, urban, and culturally diverse group" (Bullock, 2012, p. 94). This is fascinating as many feminists opposed to Islam and its 'patriarchal' teachings blame Islam for not allowing women to attend school, work and pursue careers. However, this is not true as many authors recognize that Muslim women are highly educated and working in various fields (Bullock ,2012; Zirvi, 2010; and Beyer et al, 2013).

Almost all the existing literature about Muslims focuses on mainstream Muslims which are either majority "Sunni" or "Shia". There is no specific research on the Ahmadiyya Muslim sect in Canada and how their identities differ from other Muslim sects. Even in studies which mentions Ahmadis, they are mentioned very briefly. The reason this sect is often ignored is because it is a minority Muslim group that faces discrimination and persecution within some Muslims communities, where they are not considered Muslims. Some minority group such as Shia's and Ismailis are recognized as minorities within the minorities, and they often face discrimination in Muslim communities as well as in the larger Canadian society. Ahmadi Muslims are heavily persecuted in Pakistan but often neglected in the literature. In 1974, the then prime minister of Pakistan, Zulfiqar Ali Bhutto declared Ahmadi Muslims "non-Muslim." Since then, Ahmadi Muslims are not legally considered Muslims and are persecuted both legally and socially and are not allowed to openly practice their faith. 
The name of the sect is known as 'Ahmadiyyat' (also known as 'Ahmadiyya Muslim Jama 'at) and the followers are known as Ahmadi Muslims. The Ahmadi Muslim Jama 'at is not a new religion but rather a sect of Islam which is known as the revival of Islam by its believers. The names, Ahmadi, Ahmadiyyat and, Ahmadiyya Muslim Jama 'at (Community) are simply to differentiate Ahmadi Muslims from other Muslims. It was founded in 1889 by the Promised Messiah $^{\text {as }}$ and Imam Mahdi (The guided one), Hadhrat Mirza Ghulam Ahmad ${ }^{\text {as }}$ in a small village called Qadian, in Punjab, India. Hadhrat Mirza Ghulam Ahmad ${ }^{\text {as }}$ was a devoted follower of the Holy Prophet Muhammad ${ }^{\text {saw }}$ (Zirvi, 2010). While Ahmadi Muslims have differences in some beliefs, from other Muslims, there are two major differences. First, they believe Jesus Christ ${ }^{\text {as }}$ did not die on the cross, rather he died a natural death. Therefore, the question of a physical return of Jesus as is irrelevant. Secondly, they interpret the second advent of Jesus ${ }^{\text {as }}$ as a spiritual occurrence, as like that of second coming of Elijah, as described by Jesus ${ }^{\text {as }}$ himself. Just as John the Baptist had come fulfilling the prophecy of the second coming of Elijah, Hadhrat Mirza Ghulam Ahmad ${ }^{\text {as }}$ has come fulfilling the prophecy of the second advent of Jesus ${ }^{\text {as }}$. Ahmadis believe that Hadhrat Mirza Ghulam Ahmad of Qadian ${ }^{\text {as }}$ is both the Messiah and the Mahdi that was prophesied (Zirvi, 2010).

Further, Ahmadis believe that after the Promised Messiah a system of Khilafat (succession) was established. Although these khalifas are appointed by a council, they are believed to be guided by God. Currently four Khalifas have passed away and the current khalifa is the fifth one (which I discuss later). Although many other Muslims claim Ahmadis do not practice the true teachings of Islam, this is not the case. Muslims still follow the exact teachings of the Holy Prophet Muhammad saw. As Zirve writes in his book "Welcome to Ahmadiyyat, The True Islam" (2010): 
"Ahmadiyyat is Islam in its pristine purity, and not a new religion. It is the Renaissance of Islam in the Latter Days. Ahmadi Muslims strictly follow the original religion of Islam and have not added or taken out anything, as far as the fundamental beliefs and acts of worship are concerned. The members of the Ahmadiyya Community are required to illustrate in their daily lives all the social, moral and spiritual values inculcated by Islam, of which the highest example was furnished in the life of the Holy Prophet ${ }^{\text {saw }}$ of Islam....” (p. 221).

The major contention that other Muslims have against Ahmadis is that they do not believe in the finality of prophethood and do not consider Prophet Muhammad saw as the last prophet. However, this allegation is not true. The Promised Messiah ${ }^{\text {as }}$ himself clarifies this in a book he wrote called "A misconception removed" where he says,

"Remember wherever I have denied being a Prophet (Nabuwwat), I have denied it in the sense that I am neither an independent bearer of a Law or Shari'ah, nor am I an independent Prophet, a Prophet in my own right. But in the sense that I have received spiritual grace from my Mentor and Master, my Rasul, that I have been awarded his name and have been gifted with knowledge of the unseen through him, and because of him, I am a Rasul and Nabi but without a Shari 'ah (Ahmad, 2007, p. 10).

The Promised Messiah ${ }^{\text {as }}$ himself is a believer of the Prophet Muhammad ${ }^{\text {saw }}$ and was only sent to the revive those teachings. He further states:

"Our belief, which we hold in this life here on earth and to which we will continue to adhere firmly till the time that we pass on to the next world, is that our spiritual leader and master, Muhammad $^{\text {saw }}$ is the Seal of Prophets and the Best of the Messengers" (Ruhani Khaza'in, Vol. 3: Izala-i-Auham, p 170). The difference lies in the interpterion of the term Prophet as Ahmadis believe there are three different types of prophets:

1. There are those Prophets who are commissioned by God to introduce a new Shari'ah, a new code of law. These are called the Law-bearing Prophets.

2. A Prophet who is a reflection of an earlier law-bearing Prophet. It is not independent but derives its Divine origin through total submission and homage to a previous Lawbearing Prophet. 
3. Prophets who are not Law-bearers but only serve the previous of an earlier Shari'ah Law-bearing Prophet (Zirvi, 2010, p. 283)

It is these differences which have been used as excuses for the persecution of Ahmadis in Pakistan. Since 1974, Ahmadi Muslims in Pakistan have been harassed and discriminated against. Many Ahmadis have been killed for practicing their faith which also included an attack on an Ahmadi Mosque in 2010 (Al Islam, 2018). As a result, Ahmadi Muslims have migrated out of Pakistan to flee persecution and to be able to practice their religion freely. An example of this persecution is the attack on their mosques in May 2010. As reported by the BBC, "Gunmen have launched simultaneous raids on two mosques of the minority Ahmadi Islamic sect in Lahore, killing more than 80 people, Pakistani police say. The attackers fired guns and threw grenades at worshippers during Friday prayers. Three militants later blew themselves up with suicide vests" ("Pakistan mosque attacks", 2010, p. 1). Although this was the first major attack on a place of worship of Ahmadi Muslims, there have been countless incidences of brutal killings, imprisonment and harassment which have been going on for years and continue to take place today.

The current leader of the Ahmadiyya Muslim Jamat, His Holiness Mirza Masroor Ahmad aa is the fifth Khalifa (Caliph) of the Ahmadiyya Muslim Community and is based in London England. Ahmadi followers around the world follow guidance of his Holiness through his speeches, Friday sermons, letters and personal visits. Unfortunately, his Holiness is unable to travel to Pakistan due to the persecution of Ahmadis. Therefore, the discrimination that Ahmadis faced both back home in Pakistan and in Canada, can be a significant contributor to their personal and group identity here in Canada. Because of this discrimination Ahmadi Muslims have become 'a minority within a minority'. As they are not legally 'allowed' to call themselves 
Muslims in Pakistan, this can affect how Ahmadis view and present themselves here in Canada.

For instance, some Ahmadi Pakistani immigrants may become so accustomed to just saying they are "Muslims" rather than Ahmadi Muslims because they are afraid of being persecuted.

Although Muslims have been settled in Canada for a long time, the Ahmadis are a relatively new community in Canada. The Ahmadi Muslim community was established in Canada around 1960s and the community was first officially registered as a religious organization in Canada in 1966 in Ontario as the Ahmadiyya Movement in Islam (Ont.) Inc. In 1985 , the community bought a 25 -acre plot of land, with a large farmhouse on it, in the northern suburbs of Toronto (which is now Vaughn city). It became the fundamental mission-house for the Canadian Ahmadiyya Community and it was on this plot of land that the Baitul Islam Mosque was built, inaugurated by Hadhrat Khalifatul Masih IV, Mirza Tahir Ahmad ${ }^{\text {ra }}$ (fourth worldwide Head of the Ahmadiyya Community), in 1992. Towards the end of the 1990s, the zoning of the area around the mosque was altered from agricultural to residential land. Subsequently, the whole neighborhood became like a huge construction site. Adjacent to the property, was a 50-acre plot of land, where builders and developers started planning the construction of houses for sale to the public. Members of the Ahmadiyya Muslim Jama 'at availed of the unique occasion to live within walking distance of a mosque and the vast majority of houses were purchased by them. This is how "Peace Village" formed. Thus, Peace Village is situated on the northern and southern sides of the property and is not owned by the Ahmadiyya Jama'at, but most houses in this area have been bought by Ahmadis. The Community was able to get involved in the municipal planning of the area, and thus some street names are associated to the history of the Ahmadi Muslim Jama 'at, like Ahmadiyya Avenue, Tahir Street and Nasir 
Street (Malik, 2013). Peace Village is the central place of meeting for Ahmadis in Canada as the Canadian headquarters and main institutions are based here.

Interestingly, when Peace Village was first established, the community had to battle some negative media propaganda internationally and from other parts of Canada (different from positive reports in the local media). Some media sources complained that Muslims had started making ghettos in Western countries and Peace Village was mentioned as being one such ghetto. The main attack came in the form of an article in Le Figaro, the Paris (France)-based newspaper. It portrayed Peace Village as a female-suppressing, closed Islamic ghetto, which cowardly white Canadians had permitted to insert itself in the heart of (Judeo-Christian) North American Western society. As narrated by the President of the Ahmadi community, the community began receiving a series of requests for interviews about Peace Village from media outlets, from Europe and elsewhere, some of whose staff were based in Montreal. He mentions in the book, 'Review of Religions' (Malik, 2013) that media personnel would come over, visit Peace Village for a couple of days, gain access to go into people's homes and see for themselves the comfortable houses and, at the same time, the Islam-focused yet reasonable style of living. The media personnel spent time conducting interviews with the leaders of the Community and held discussions with groups of Ahmadi Muslim women separately, such as working professionals, housewives and university students. They also interviewed non-Muslim residents of Peace Village. Finally, one of these journalists admitted that she could not find it in herself to produce the type of report that she had been expected to make. She clarified that image of Muslims presented in the Figaro article was not an honest representation of life in Peace Village. The media were astounded to observe how closely Ahmadis were integrating with and adding value to the local community (Malik, 2013). As a result, they wrote about the Ahmadi Muslim 
community very positively and what started as a hostile media attack, ended up as a series of very positive reports on Peace Village that disputed the picture created by the original article. The latest of those reports was broadcasted on the Swiss RTS channel on 5th December 2012 (Khan, 2013)

Today, the Ahmadi Muslim community is established all over Canada, including Western Canada. There is a large Ahmadi population in the GTA as well, with the construction of a new mosque in Brampton underway. In March 2018, Ahmadi Muslim women in Canada launched a national campaign aimed at educating other people about the Islamic principles of women's empowerment. Essentially, through the campaign women across Canada shared their experiences on how Islam gave women rights from the very beginning and empowered them. (Ahmadiyya Muslim Jamat, 2018). Ahmadi women play a crucial role in the Ahmadi Jama 'at where they have various auxiliary organizations and have different positions of leadership. They work collaboratively with men but make their own decision in matters such as holding classes for girls and women, organizing events for health, spirituality and religious knowledge, student youth meetings, and finances (Zirvi, 2010).

\section{Chapter 5: Methodology}

Before conducting a study, an author must actively and consciously understand the lens which they bring to the study. He or she must determine how prior beliefs will influence the study because everyone has their own experiences. These positions of the investigator may influence the research in three major ways. First, they can affect access to the field because respondents may be more open to share their experiences with a researcher whom they perceive as understanding to their situation and the researcher may be more knowledgeable about possibly supportive and informative resources. Second, they may shape the nature of researcher- 
researched relationship, which then, affects the information that participants are ready to share. Lastly, the worldview and background of the researcher affects the way in which he or she constructs the world, uses language, asks questions, and selects the lens for filtering the information collected from participants and making sense of it, and thus may shape the findings and conclusions of the study (Berger, 2013, De Tona, 2007; Kacen and Chaitin,_2006). Thus, before I began the study I had self-disclosed about potential influences and where I came from as an individual and a researcher to the self and for the MRP reader.

As a researcher who belongs to the same community as my participants, I have my own experiences and family background. Growing up as an Ahmadi Muslim my family had to flee from persecution from Pakistan to Germany for a better life; one without fear and persecution. Interestingly, my father was born a Sunni Muslim and believed that Ahmadi Muslims were not real Muslims. In fact, he contributed to physical assaults on the shops and houses of Ahmadi Muslims alongside his friends and family. However, soon he started researching on Ahmadi Muslims and realizing the truth about the community, he eventually converted and married my mother who was already an Ahmadi. His family however, did not accept him and he was kicked out of his house. They hoped for a better life in Germany and thus lived there for six years. Germany, however, did not accept us and we were eventually deported back to Pakistan where we lived for three years. My mom, my siblings and I lived in Pakistan while my dad settled in Canada. I was born in Germany along with my twin sister, yet not granted any status. After living in Pakistan for three years, we moved to Canada to be accepted yet again and have a better life. No doubt we were given the freedom to practice our religion peacefully. I grew up in Canada attending the mosque regularly, attending events and getting together with my Ahmadi sisters. I am also a Canadian citizen and I participate fully in 'Canadian activities'. I speak fluent 
English, vote, attend university and am proud to be Canadian. Yet, I still find myself questioning the authenticity of my 'Canadianness' alongside my Ahmadi Muslim identity. I am constantly trying to prove that I am truly Canadian and need to show my gratitude to Canada for allowing me to live here. We may have escaped the persecution back home, but the discrimination and feeling of otherness still exists. As an Ahmadi Muslim immigrant, I must prove that I value my Canadian identity because I wear my religion on my head. I am forced to perform an identity in public to convince others I am truly Canadian. It is with this understanding and experience that I wish to explore the experiences of other young Ahmadi Muslim women but those who are born and raised in Canada. My experiences of immigration are not the same as women born in Canada and thus I rely on their stories to create knowledge of their identities.

I self-identify as an Ahmadi Muslim Canadian who wears the hijab and am an able-bodied female. I belong to the same group as the participants I had engaged with. Further, I immigrated to Canada from Pakistan at the age of 9; where majority of Ahmadis live. Therefore, I am also of South Asian descent. This may have influenced my research as I have similar lived experiences of identity as a Canadian and an Ahmadi Muslim because I have struggled with identity, but I understand and define my identity in a very particular way. I have had experiences of immigration, identity confusion, negotiating my identity and discrimination. Therefore, my experiences may influence the way I interpret their understandings of identity and being a Canadian Muslim. Further, as a woman who has faced discrimination based on identity I feel like I am an insider to the community. This was an advantage for me as they were able to relate to my experiences and be more open with me. This was a positive influence I had on my research as I was able to build rapport with my participants. However, "there is an issue that you could define as the interaction between personal experience and research experience which always need to be 
reflected upon (De Tona, 2006, p. 9). This is where I must be cautious and reflect on how I will differentiate between my experiences and their experiences. I must remain neutral and not impose my idea and definition of identity on to my participants. Lastly, as someone who identifies very strongly with the Ahmadiyya Muslim Jama 'at, I am quite knowledgeable about the Ahmadiyya Muslim Jama 'at. However, the way my participants interpret religious beliefs may differ from my interpretation and thus I must be mindful of that throughout my research. Although we may practice the same religion, their interpretation of the religion and how they apply it to their daily lives may be very different from mine. Thus, when I present my findings, I need to be aware that I communicate what the participants were trying to say and not what I wanted to hear. However, I may add that being a part of the community was definitely a benefit as the participants were very comfortable and open with me when talking about topics such as discrimination, race and belonging which may not have been the case if the researcher had been a non-Muslim, particularly a White researcher, who may be seen as the 'other' by the selected participants. However, as I was a visible member of the Ahmadi community, some participants may have felt the need to attune their responses to my liking and may have censored some of the responses.

This study used a qualitative research approach and phenomenology as a strategy. Phenomenology is a strategy in which "the researcher describes the lived experiences of individuals about a phenomenon as defined by participants. This description culminates in the heart of the experience for numerous individuals who have all experienced the phenomenon (Giorgi 2009; Moustakas 1994). I collected primary data through face-to-face interviews to understand the lived experiences of young Canadian Ahmadi Muslim women. The use of phenomenology is coherent with the use of interviews as both are using the participants lived 
experiences; especially because this particular topic has not been studied before. The Ahmadi Muslim girls all had experiences as Ahmadi Muslims and Canadians in relation to their identity and they described their experiences to me and how those impact their identity formation. The interviews allowed me to gain detailed responses which provided me with insight into the lives of these young women as Canadians and Ahmadi Muslims. They also allowed for individuals to share their personal stories and influences on identity.

I conducted nine un-structured interviews which were all audio recorded and then transcribed verbatim. All the interviews were recorded on a protected device and deleted after transcriptions. I also took brief notes throughout the interviews in a notebook. All participants were given culturally appropriate pseudonyms to protect their identity. As a member of the community, the ethical issues which I encountered were that I may meet someone who knows my participants. As we attend the same mosques and many events, it is very likely we end up meeting outside of the research context. I had the responsibility to not reveal them as a participant unless they themselves wished to disclose their participation in my study to family members or community members. Lastly, I knew I had enough data when I began preliminary analysis and saw the recurring patterns in the codes. When there was no longer any new information or ideas coming up, I knew I had reached the stage of saturation and stopped collecting data.

Data were analyzed through the use of constructivist grounded theory using different types of coding, starting with open (initial), then axial, and finally selective coding. Constructivist grounded theory according to Charmaz is "entering participants" worlds and meanings to understand and then interpret human processes from the ground up" (Riessman, 2010, p. 391). Further, a code can be described as a "word or short phrase that symbolically allocates a combined, prominent, essence-capturing, and/or evocative attribute for a portion of language 
based or visual data" (Saldana, 2016, p. 4). I began with the use of open coding or initial coding where I read through all the data (transcripts). This was my starting point to understand my data and start finding similarities and differences between the participants' responses. Then, I used axial coding to begin identifying the dominant codes within the responses as Boejie (2010) explains that the purpose of axial coding is to determine which codes are the dominant ones and which are the less important ones and to rearrange the data set by crossing out synonyms, removing redundant codes and selecting the codes that are the most representative. Lastly, I used selective coding (focused coding) to create final themes and categories which were relevant in answering the main research question. I took the most significant codes from axial coding and created themes which represented what the participants were trying to say. The goal in selective coding is to create categories without distracted attention at this time to their properties and dimensions (Saldana, 2016).

\section{Participants}

I recruited nine women between the ages of 19-26 from the GTA and surrounding areas using snowball sampling within the Ahmadi Muslim community. This of course was a limitation because the sample is very small and not representative of the entire Ahmadi Jama 'at in the GTA. Initially, I was looking to recruit women from ages19-26 but was only able to recruit women between the ages of 20 and 26 . The reason this age group was recruited for the study was because identity formation is a key task of early adolescence and continues into early adulthood as young people continue to explore. This age group is also when most people are attending university or college and starting to work (Berk, 2012) Originally, I had intended to include 1825-year old's, but because of ethical considerations of minors, I extended the age from 19-26. Thus, because I was looking at identity formation, this age group was ideal. Further, the use of 
snowball sampling was a limitation because only a small circle of participants were recruited. The women were all born in Canada and identified as both Canadians and Ahmadis and had parents who immigrated from a South Asian country (Pakistan, India, Bangladesh). Anyone who was not from South Asia or between the ages of 19-26 was not recruited. This is because the majority of Ahmadis come from these three countries and I wanted to explore the experiences of young women, so anyone above 26 was not recruited. Out of the nine, one had parents who immigrated from Bangladesh and eight were from Pakistan. Unfortunately, I was not able to recruit any participants who had parents from India. Given that all participants are in their early 20 's, all participants were either currently working or studying in a post-secondary institution. Only one participant was married, while another was going to be engaged in the next month. The details of the participants can be seen in the table below.

\begin{tabular}{|l|l|l|l|l|l|}
\hline $\begin{array}{l}\text { Participant } \\
\text { (pseudonyms) }\end{array}$ & Age & $\begin{array}{l}\text { Wore } \\
\text { Hijab? }\end{array}$ & City/Location & $\begin{array}{l}\text { Parents } \\
\text { background }\end{array}$ & Work/current \\
\hline P1: Madiha & 26 & Yes & Vaughn & Bengali & Working \\
\hline P2: Naima & 24 & No & Brampton & Pakistani & Working/Studying \\
\hline P3: Hina & 24 & No & Vaughn & Pakistani & Working \\
\hline P4: Humeera & 23 & Yes & Brampton & Pakistani & Working/Studying \\
\hline P5: Sonia & 21 & Yes & Brampton & Pakistani & Working/Studying \\
\hline P6: Saira & 21 & Yes & Brampton & Pakistani & $\begin{array}{l}\text { Working/ } \\
\text { Studying }\end{array}$ \\
\hline P7: Ameera & 20 & No & Vaughn & Pakistani & Working/Studying \\
\hline P8: Samia & 26 & Yes & Brampton & Pakistani & Working \\
\hline
\end{tabular}




\begin{tabular}{|l|l|l|l|l|l|}
\hline P9: Sana & 20 & Yes & Toronto & Pakistani & Studying/Working \\
\hline
\end{tabular}

After conducting the interviews, there were some methodological considerations which I would keep in mind for the future. Some future considerations for methodology are that I would have liked to recruit women who lived in rural areas, with less diversity to see how location impacted their identity. Further, some of the questions that I asked in the interviews required some follow up questions which I was unable to do. This would provide a richer data set that thoroughly explores some of the topics such as dating, and relationships. Subsequently, for the future, I would like to focus more on questions which talk about the clash or conflict between values such as dating, dressing, relationships and drugs to gain a deeper understanding of the cultural clash and inner conflict.

\section{Chapter 6: Findings}

The study aimed to explore the identities of young women who identified as both Canadian and Ahmadi Muslim and factors that shaped their identity formation.

\section{Being Canadian}

The participants in the study had parents who had immigrated to Canada in different times. They all had their own interpretation and understanding of what it meant to be Canadian, but it was somehow often related to their parents' home countries in many ways, as they were aware of the differences that existed between the countries. Some of the women compared their parents' home countries to Canada and expressed their appreciation of Canadian values such as freedom of expression, security, acceptance and multiculturalism. Participants repeatedly associated multi culturalism, acceptance of all religions and cultures, being flexible and celebrating differences as a strong marker of Canadian identity. 
When participants were asked to talk about what it means to be Canadian, they struggled to describe being Canadian. Many were unsure of what constituted a Canadian identity and hesitated before answering. This is especially evident in terms of defining Canadian values. This is particularly intriguing as seven participants had identified as Canadians before Ahmadi Muslim but had a better sense of being Ahmadi than Canadian. Nonetheless, many participants were proud to be Canadian and were happy to call themselves Canadians. However, one participant brought up a very interesting point when she said:

Naima: You can walk outside and in five minutes you can see someone from every race....no one is actually truly "Canadian" .....very few people are truly "Canadian" ...if you know what I mean (Laughs). Their ancestors are like from here like or they're like Indigenous people ....well like there are Indigenous people here but like majority of the people you meet in your life here, will not be.

Further, being Canadian was described in two ways by participants. The first part of being Canadian included the different ideologies and mannerism. It was about describing how Canadians thought, acted on a day to day basis and what they valued, and secondly the participants talked about the 'cliché' activities and hobbies that are often associated with being Canadian such as hockey, eating poutine and going out. These two categories are discussed in detail below.

For several of the participants being Canadian meant accepting all cultures and religions and being multicultural. It meant living in a place where different cultures and religions existed together. All participants but two noted multiculturalism, diversity and being accepting as being a big part of their Canadian identity. In fact, it was the first thing most participants mentioned in terms of their Canadian identity.

Saira: We used to have like the multi-cultural nights where it was like you would have a potluck and there would be like a showcase of like different cultural dances or like songs or like music or whatever umm and I feel like that's what being a Canadian is. Knowing that you're different but celebrating those differences 
Naima: I feel like living in a country like Canada it's so multicultural, so diverse, that growing up you don't feel as if you're kind of like an outsider, you kind of just feel like we were all meant to be here............To me Canadian means that you are...first of all accepting of all races and all religions and cultures because I feel like that is exactly what our country is. You can walk outside and in five minutes you can see someone from every race

Sonia: like I said Canada is very diverse and accepting so I can dress how I want and not feel like I'm being so judged...

Although some participants were aware that Canada has some work to do in terms of being accepting to all people, they none the less recognized Canada's diverse and multicultural ideology. As one participant noted that even politicians are accepting

Sonia: Okay......umm......well I think the biggest thing is that Canada is so diverse and accepting of different cultures and religions that's even like our prime minister and all like the politicians. That's what it is to be Canadian. To be accepting of different cultures and.... and experiences and religions

Being Canadian also meant having freedom and a sense of safety to the participants. As women, they had the ability to stay out late and know they will be protected, whereas in their parents' home countries they would not have protection. Further, being Canadian meant having freedom to practice your religion without being persecuted or discriminated.

Madiha: "That's totally fine and so my parents are like, would you be able to do this in Bangladesh? And it's a certain no. So umm.... that's why like the safety and the freedom that we have in this country is great. Umm...the opportunities that we get"

Samia: To be a Canadian (laughs)....that's a really good question. Umm being Canadian is something I'm really proud of because like our country pretty much signifies having freedom, and diversity and accepting other people because we live in a very diverse country

Many participants also stated that being Canadian meant to be polite and nice. Four

participants responded that being Canadian was to be nice, kind and loving or polite.

Sana: Canadian.......I feel like this sounds really corny or like cliché. To be kind. To be loving. To be respectful. And when I say respectful, I mean of anyone's culture, religion, anything. I feel like Canadians are very very accepting of like other people no matter like what .... where they come from. No matter what religion they practice so... 
Humeera: I don't know it's just uhh its being extremely polite (laughs) to everyone you know, even though....I was literally walking down the street one day ...I work in a not so nice neighborhood and someone asked me if I wanted to smoke a joint with him and its not ignoring the person, its turning around and saying "no, thank you though, and have a nice day", like that's what I feel like being Canadian is

Naima: I think Canadians are just nice people....(laughs)......... Like I've travelled quite a bit so I feel like the nicest people I've met is here

The participant above was very specific to compare Canadians to people from different countries such as Egypt, Denmark and America. She was very proud to say that Canadians were the nicest people she had encountered and really felt that was a big part of being Canadian especially because she had faced discrimination outside of Canada.

Three participants noted that watching hockey, the local teams and following the national team was a big part of being Canadian for them as it showed a sense of pride of the country. One participant also noted watching fireworks on Canada as a part of being Canadian.

Hina: And watching Leafs games even though they suck every year and it's about watching fireworks on Canada day ..every day .... you know

Humeera: So to be Canadian obviously the first thing is like hockey (laughs). Which I find because I am a hijabi people suddenly get shocked that you're into hockey? You know hockey teams? And I'm, like yes...I went through a very strong phase in high school from like grade nine to twelve where I was obsessed with hockey and that was one thing that always threw people off

Samia: I love hockey with like a passion, I absolutely love hockey like I still have jerseys, hockey jerseys of team Canada especially. Us as a family, we always sit down and watch hockey, The world junior championships and even watching the leafs play. So .......yeah that's it

Humeera's response is particularly intriguing as she mentions that she absolutely loved hockey and had knowledge of the different teams. However, as a 'hijabi', She was often questioned on how she could possibly enjoy hockey because that was a very 'White' sport and a 'Canadian' thing. Although she did not indicate this as discrimination, it was obvious that her interactions with white students indicated the meaning of 'Canadian' was associated with the 
colour of your skin. It also demonstrated that for Humeera, a part of being Canadian was

watching hockey but her white peers did not view her as Canadian. There was a clear difference in how Humeera perceived herself and how other 'Canadians' viewed her. In her response,

Humeera was very passionate about hockey and felt she was just as Canadian as anyone else by participating in the hockey culture. However, this was not the same understanding that her peers had. As she notes:

Humeera: Which I find because I am a hijabi people suddenly get shocked that you're into hockey? You know hockey teams? And I'm, like yes...I went through a very strong phase in high school from like grade nine to twelve where I was obsessed with hockey and that was one thing that always threw people off. They were like how could you be into hockey. Like that's a very White sport, it's Canadian ... you are a hijabi... a 'paki'(a derogatory term for Pakistanis)... what do you mean... but that for me

Whether it was intentional or not, the students associated hockey with white people and being Canadian which demonstrated a specific ideology that is associated with hockey culture. Although Canada may be diverse and multicultural, some things like hockey are still not diversified and hockey is still something only 'real Canadians' understand and enjoy.

Further, the participants perceived themselves to be Canadian even if others did not. For example, two participants told stories of a professor and a peer who swore and then apologized to them because they saw them as Muslims and thus had to show them respect and treat them differently.

Madiha: he said like shit or $f$ whatever and he said that and immediately he looked at me and he says oh I'm so sorry ma...umm I'm so sorry I'm so sorry and I didn't really mean to use that word because he thought he was offending me (laughs) because he thought I never swore but then I said you know its okay ....just treat me the way you that treat all your other classmates you don't have to you know not swear because I am there but I found that funny and I assumed that it was because you know a hijabi sitting in his class and you have to ..I dunno maybe he thought he had to treat us differently or he had to be more respectful but that was really interesting to see that just because there was a hijabi sitting in your class you automatically just respect them more because of the way they are dressed. 
Humeera: he was saying something to some girl and he was swearing and then he saw that I was there and suddenly goes "I'm so sorry, I'm so sorry.... and I was like umm I don't care what you say but because I wear the hijab he realized I need to be watchful of my language.... so that was good I guess....

The participant even explicitly tells the professor to "treat her like everyone else" which she meant were the white classmates as her program consisted of all white students. Even though there were many other people in the classroom, no one else received an apology. The professor and classmate had assumed that Muslims do not swear or do not like to be sworn around. This was an assumption based on the Hijab which automatically made them look different than the other students. This demonstrates that identity can be internal and external because you may identify as something, but other may perceive you as another. Internally, these participants indeed felt a sense of wellbeing as mentioned by Erikson. However, the message that was sent from the professor and peers was that they were different. The social and cultural aspect varied as the people around these women did not share the same views on being Canadian. Although this was not communicated explicitly, many were given hidden messages on who was really a 'Canadian' and it may not have had a negative impact on the women but was still a reminder that they were not truly Canadian. There was a clear discrepancy between the way the women understood their Canadian identity and how other white Canadians viewed them. Similarly, in recognizing the true nature of being Canadian, one fascinating aspect of Canadian identity mentioned by a participant was being just like the 'Catholic girls' in high school.

Ameera: For me growing up to be a Canadian obviously meant uhh meant to be like all the other Catholic kids over there in my high school. Which was umm you had to have...this might sound so silly but all the girls had like TNA tights you know. Crop shirts umm ...juts like straightened hair. But that's just look wise. But lifestyle wise, they were allowed to do stuff or more like open to like activities that I wasn't.

This participant had attended a Catholic school and felt that being Canadian at that time was being just like the other girls who were Catholic. This meant dressing like them, doing the 
things they did such as watch specific shows and using social media etc. When referring to

"Catholic girls" she was talking about the white girls in her school who had different ways of dressing from Muslim girls in her Ahmadi Muslim community

Other than hockey, some participants attributed things like eating poutine, going out with friends and watching fireworks as being Canadian. These were seen as the typical activities of young Canadians who were currently in school or working. Many participants also brought up things such as going for a drink after work as a typical Canadian activity which was a way for people to build relationships. They noted they obviously did not drink but would find other ways to socialize with their coworkers.

Hina: But yeah in terms of what it means, it means being you know a typical Canadian.... you know twenty something and going to a bar with your friends but also recognizing that you come from a religion that does not you know or suggests that you don't drink and do certain things and honoring those things but still going out and having a good time with people you know. Umm so I think that's the biggest thing...its living whatever life you wana live but still within the terms of what you've been taught, what values you were taught as a child...

\section{Being Ahmadi Muslim}

Being an Ahmadi Muslim was an identity which all participants embraced and recognized as being an important aspect of their identity. Being Ahmadi was slightly different than being Muslim. Even though the values of Islam and Ahmadiyyat were the same, the way the participants understood their identities as Muslim and Ahmadi varied slightly. Being Muslim was more about praying five times, fasting, reading the Quran and being modest. Although many said they were Ahmadi by following the basic Islamic values and morals, Islamic identity was more of a private and individual way of being whereas being Ahmadi meant having a sense of community and to be united with all other Ahmadis both in Canada and around the world.

Because the Ahmadi community is established around the world with one leader, many 
expressed that as being exclusive to being Ahmadi compared to other Muslim communities. It was also about having a specific system in place which was very structured and gave women very prominent roles. When asked what it meant to be an Ahmadi Muslim all nine participants mentioned a sense of community (Jama 'at) and unity as being the most important aspect of their Ahmadi identity. In particular, it meant having the Jama 'at and being involved in the Jama 'at as highly important.

Madiha: Rightt...umm when you're an Ahmadi in Canada its very like important to be ....part of a group...umm ... uhhh or part of a community. Like I feel like what would...how would I be if I was not Ahmadi? If I was just any Muslim, how would I be? Umm think of some of my other friends who are Muslims, but they are not Ahmadis...there's like Sunnis and Shiites and stuff. Umm and I kind of think of their situation and how they are you know ...they have...they'll go the mosque, they'll just to read namaz and uhh read their prayers and uhh that's it. They don't really have any close community like we have in the Ahmadi com...uhh Jama 'at"

Hina: I think the biggest thing for me is having a sense of community. Umm I've seen other Muslims who don't really have anywhere to go or celebrate when times of joy come and that's never been the case for an Ahmadi. There is always a somewhere to go, always something to do with another group of people which I value.

Sonia: if they are not as involved in the Jama 'at then it's not as whole to be Ahmadi, it's a big part to be involved and to be helpful and attend all the events that we have that are so helpful and so interesting and to help organize that and to actually be able to attend them .... that's a big part of being Ahmadi.

The women mentioned the differences they see between themselves as Ahmadis and other Muslim communities; which is in the tightness of the community and sense of closeness. Although other Muslims do have communities, the literature does show a different understanding of just being Muslim as it is more about personal levels of religiosity. Not only was it important to help out, but attending the events was just as important because that showed commitment to being an Ahmadi. Moreover, the women claimed that the Jama 'at had a specific structure at the local, regional and national level with women having their own roles and responsibilities and being attached to the community. 
Sana: Umm, like even when I volunteer, when I do Nasirat work. It makes me so happy that I can benefit another person. Even when I pray, I thank God for giving me like Jama 'at work to do and personally.... like sometimes people think of Jama \'at work as a burden or that they have been asked to do it but I feel privileged that somebody gave me something to do, you know. I feel privileged that I am able to have an auda (position/role). I am able to do things and able to help people, teach Nasirat. If I can teach them, one thing in a class I'm so happy. I'm more than happy so......I think that being Ahmadi for me is like a really big part of my life,

The Jama 'at was a major component of their Ahmadi identity as it was the main reason they were able to balance their identities. The strong structure and roles that women had in the Jama 'at allowed them to stay away from values that were not a part of Islam because they knew they could always come back to their Jama' at and be accepted.

They further mentioned the bond with their Khalifa as being important because he was essential in guiding their everyday lives through the Friday sermons, classes and responses to letters.

Madiha: "Compared to some of my other...friends who are not Ahmadis but Muslims ... and umm the fact that umm the Ahmadi community have one leader who is a khalifa...the fifth khalifa. We have one leader. We just feel like as a umm...greater sense of togetherness and we have person to look up to. We have any questions or we wana know something, we look up to him

Sonia: oh one of the main components of being Ahmadi is the system of khilafat and the entire Jama'at system you know we have in each country.

Having a support system through the Jama 'at was essential because it was available at all levels and helped form a lot of relationships and foster growth in their religious beliefs.

Out of nine participants, six wore the Hijab and were thus visible Muslims. However, something that both veiling and non-veiling women brought up was the topic of modesty. The women who did not wear the Hijab mentioned that just because they did not wear the hijab, they still dressed modestly to display their Islamic values and identity. Women who did wear the 
Hijab displayed modesty through wearing the Hijab but also other actions that underscored their

Muslim identity as they were already recognized as being Muslim.

Hina: visibly Ahmadi...I mean I still do my best in terms of dressing modestly in ...participating... showcasing myself as a Muslim. Like all my coworkers at work know I pray at work. I took the day off for Eid and they asked me how it went

Saira: Umm well I mean like one thing I think is just like modesty is very well emphasized in Islam and umm ..... what was I.....oh yeah modesty so umm like I feel like being a Muslim, such a big part of being Muslim is about Modesty internally and externally

\section{Being Ahmadi Muslim and Canadian}

When the participants were asked if they would identify as Canadian Ahmadi or Ahmadi Canadian, seven reported that they would put Canadian first while the other two put Ahmadi first. However, when asked about their identity in terms of who they are generally, four responded they would identify as just Muslim, three would identify as Canadian and two did not include their Muslim or Canadian identity and responded with either Pakistani or student. This finding demonstrated a strong association with being Canadian. However, even the women who identified as Ahmadi first, acknowledged that the two identities should be practiced together by mixing the values.

Sana: I think I would say Ahmadi Canadian because I feel like you have to give precedence to Ahmadiyyat before like being a Canadian. You should put your Ahmadi values before Canadian values. You should be an Ahmadi.....like you should be a Canadian based on your Ahmadi values. You know what I mean. So you shouldn't like assimilate with Canadian values like you should just like..........I don't know how to explain it (laughs).

Further, at least three participants indicated similarities in Ahmadi values and Canadian values. 
Sonia: To be accepting of different cultures and... and experiences and religions, think that's a big part of being Canadian. It also goes with being Ahmadi ...love of your country. So that's how the two relate to me...

Humeera: I've never thought about it but if I were to think about it now I think I would say Ahmadi Muslim Canadian. Just because a lot of my decisions are influenced by my religion but that does not mean I am guna go against what my country says because a part of my oath in my religion is to umm be loyal to my country and my nation so like if anything happens I am going to be first there to support Canada and to be there for whatever difficulty they are going through umm...

They expressed that even though they identified as Ahmadi Muslim first, loyalty to their country was a part of their faith which they would not compromise.

Further, although participants themselves reported 'low levels of discrimination', there were still a few instances of discrimination and as expected, the ones who faced discrimination were the visible Muslims with the Hijab. Discrimination was also based more on culture and race for girls that did not wear the Hijab. They were teased from having "Islamic" names or because of their skin colour. Two women with the Hijab reported more serious incidents of discrimination which impacted them.

Saira: like we had just gotten off the elevator and were coming to the event. Some lady like saw our hijabs and she look like shook her head and stuff and started kissing her teeth and she like mumbled like disguising under her breath and then walked away. We were just like...we were just shook like we were like what do you mean and I like..

There was also a mention of discrimination being very subtle and not direct in Canada. A few participants noted that even if they had not faced any direct discriminations, they always noticed and were aware of the subtle discrimination present.

Saira: I hadn't really faced a lot of discrimination, but like that kind of reminded me that it still like out there and it's a prevalent issue.... and like I feel there are always subtle reminders that not everyone will accept you like, religiously, culturally like gender wise...like in so many different ways you know. 
One participant mentioned feeling discriminated when she was going into grade nine at a

Catholic high school. However, this seemed more like perceived discrimination by her peers because she had not actually had any direct experience or incident of direct discrimination but just felt she was being othered and felt isolated from the very beginning. This was attributed to her skin colour because she was visibly dark and thus, very different from her peers at the Catholic school. Also, two participants noted discrimination within the Ahmadi Muslim Jama 'at. One stated it was more of a joke rather discrimination because it was just boys making fun of the way she dressed. However, the second participant noted she felt discriminated by the Ahmadi community because she did not wear the Hijab and stayed away from the community when she was younger. This participant did however note that she had a misconception of the Jama 'at and has realized it is not what it seems., many participants did share stories of friends or family members being discriminated. For example, one participant told a story of her friend being threatened by a white man that he would rip of her Hijab.

Lastly, in terms of discrimination, three participants noted they had faced discrimination by other Muslims who were not Ahmadis. The participants were very surprised but said there definitely was a negative view about Ahmadis within other Muslim communities, even the younger generations who were born and raised in Canada. They also disclosed they were hesitant before telling other Muslims that they were Ahmadi because they were not sure how they would 
react. This further marginalizes these young women because they are minorities in both

situations and cultures.

Almost all the participants acknowledged that the Islamic values and Canadian values were different and often conflicting. Nevertheless, most participants noted that there was no internal conflict for them personally because they knew what values of each culture they wanted to maintain and had developed strong religious identities. However, there were two participants who noted an internal conflict in terms of dressing and alcohol. The two participants noted difficulty between dress styles and alcohol use when they were in high school or early into postsecondary education. Interestingly, both of those participants attended Catholic school and attributed those difficulties with the "Catholic" culture which was different from Islam.

Ameera: Which was umm you had to have...this might sound so silly, but all the girls had like TNA tights you know. Crop shirts umm ...juts like straightened hair. But that's just looks wise

Hina: you stay out all night, you go to prom cottage, you get drunk. Umm alcohol was a big thing for me growing up because I don't drink uhh and anytime

The participant referred to the differences to Catholic school environments, but this is also true for public high schools where students do dress a certain way and consume alcohol. Thus, a more accurate attribution would be to high school culture, rather than just Catholic. However, she also noted that this changed when she came out of high school and matured and understood it was her choice to make whether she wanted to drink or not and decided she was not going to drink. Another participant noted she had a little difficulty going out with friends only because her parents were strict about not letting her go to other people's houses or restaurants, so her friends would come over to her house. Essentially, she had to adjust how she interacted with her friends. 
All participants mentioned that despite the differences between the two different value systems, internal conflict was low for them. Rather, it was just about choosing what aspects of each identity aligned with their morals, values and upbringing and allowed them to live like both Ahmadi Muslims and Canadians. A lot of the participants recognized that in Canada, it wasn't about being either Canadian or Ahmadi because people have different 'faces' depending on the context.

Hina: You don't ever see the whole side of a person...very rarely do you ever see the whole side of a person...or people are multi-faceted, they are gonna show you what they wana show you and if they wana keep something to themselves then... who are you to bring that up until like....

This young woman stated that her identity changed depending on who she is interacting with, therefore giving identity a level of fluidity as mentioned by various authors in the literature. They were able to negotiate their identities by balancing the differences. They adjusted the way they did things with friends and family. For example, instead of going out for drinks, they went out for lunch. If they really liked a dress which had no sleeves, they would adapt to it by wearing a cardigan over it. One participant, however, very strongly stated that there was absolutely no internal conflict for her between Ahmadi Muslim and Canadian values because she had guidelines from her parents and she was never really attracted to 'all that stuff' (referring to 'Canadian' cultural practices) because she knew who she was from a young age. All participants who did mention an internal conflict with certain aspects of Canadian society, admitted it was a phase in high school and first year of post-secondary, which they eventually grew out of once they realized what they really valued. Many participants expressed that difficulties that they had growing up as kids were because there was a lack of understanding of why they were told certain things when they were kids. Once they were able to understand the logic behind not eating pork, or covering their bodies, it was easy to accept and adapt to those values. 


\section{Influences on Identity}

The second question that this study tried to explore were the factors which influenced and shaped the identities of these young women. The participants presented various factors as having an influence on their identity, with some heaving a heavier influence than others. These factors included, family, friends/peers, location/ where they live, parent's immigration history, institutional affiliation (the Jama 'at), bond with Khalifa, media and fashion. However, the factors with the most influence were family, institutional affiliation and residential location.

All nine participants expressed family as the first and foremost important contributor to their identity. This was especially the case with mothers and sisters being essential role models for the young women. However, one participant especially mentioned the influence of her father and his expectations of her in terms of being a good Muslim by praying five times a day and dressing modestly.

Madiha: that's like one thing my dad wants.....he's like I don't care if you do anything else in your life you pray five times a day. That's like the lowest expectation I have of you. Okay you and he says that if you do that everything else will fall in line. You read Namaz five times a day you will be fine. Umm and also like umm purdah uhh like wearing the hijab and wearing modest clothing right umm...so those umm these two things mainly my parents were very insistent on.

Sonia: $\mathrm{mhmm}$... I would say my mom....yeah for sure. She is my role model. She ..just cus she is very fair and reasonable...I really appreciate that and she is not uhh like unreasonable with us so I appreciate that from her and the way I see her handle situations, she always brings God into it, the Jam 'at

The values and morals the parents had instilled in them since the very beginning was important because it set out clear guidelines of what was acceptable. They also had a big role in teaching them about Islam by being role models and making sure they were taught the basics of Islam. They were exposed to Islam and Ahmadiyyat from a very young age which influenced how they understood their religious identities. 
What was surprising was the lack of influence that the fathers or any male figure had on the choice to wear the Hijab. Only one participant noted the fathers' influence on being modest and observing purdah. This is a significant finding because it challenges the notion that veiling is a sign of oppression from men. The women who were strong in their Ahmadi Muslim identities and wore the Hijabs, were influenced heavily by their mothers, sisters or other women within their community. This demolishes the misconception of the veil as a tool for men to oppress and force women to submit to the wills of their fathers and husbands which is quite often depicted in the media.

Other than family, participants also noted their friends as being an important influence on their identity, not because they influenced their decisions, but because they were so accepting and understanding. This allowed them to be who they are, develop stronger identities without feeling othered.

Naima: I feel like its all comes down to who your friends are... and the people you spend your time with cus it influences you the most. I feel like we've all been through a phase where we've been significantly influenced by our friends and like growing up your parents always say ... haven't you heard the saying, it's like your five closest friends are exactly who you are...I dunno who said that, but I read it somewhere once. (laughs). They're like a true representation

Saira: Even my other friends, I've been so blessed to have like some of my closest friends are just so kind and accepting of like all of our differences. Like my best friend, like we have had like hour long conversations about our different religions, cus she's Hindu and like I'm Muslim and like she's not very religious, whereas I like to think I'm more religious. But like she is still like curious about stuff and she's like ... she makes me want to learn more about like my own religion and also about others as well. Like I feel like I have been surrounded by so many positive people in my life that are just like teaching me to be more loving, more accepting, and like they're helping me be stronger in my faith, regardless of whether they believe the same things.

However, two participants did express their friends had no influence on their identity because they made their own decisions based on their values and parents' teachings. It also did not matter what their friends thought of them because they were happy with their identities. 
Another major influence on identity was the involvement in the Jama 'at and the role models they had within the community. All nine participants said having the Jama 'at, being involved, having a support system or other Ahmadi women to look up to helped them create stronger Ahmadi identities and stay away from un-Islamic activities.

Sonia: Coming to the Jam 'at events and seeing people and like jalsa seeing.....hearing everyone's experiences. That I always come back from that thinking...like I'm so glad to be Ahmadi and its it's helped me become who I am today and I hope I will continue to grow because of that...

Many participants acknowledged that the things they had learned in the classes which they attended within the Jama 'at, really stuck with them and shaped them as a person. This also included attending different events where they delivered different speeches which were very meaningful.

Another influence was the place where people lived and had grown up. It shaped their identity as it created an open mind and exposed participants to different cultures and religions. For the three participants living in "Peace village", it had a very big impact on their identity formation. Living in "Peace Village" meant they were in walking distance to the Mosque and majority of the people in the neighbourhood were Ahmadi. This meant that the values and lifestyles were very similar which allowed them to live in a comfortable manner without being othered or discriminated.

Hina: And then where I live is is....I've never not lived you know farther, or I don't remember not living in an Ahmadi community and not waking up Saturday morning and to go to a class umm a religious knowledge or a Tuesday afternoon, or whatever it was and teaching one myself when I was looking for community service hours umm so that really makes a big difference because it's those constant values that are constantly engrained.

Sana: . Umm a lot of people that live around me are my age or around my age. Umm I have relatives that live on my street. I love living in a neighbourhood with a lot of Ahmadis. I feel very connected with my community. I often go to the Ahmadiyya Abode of 
Peace mosque because I like to read namaz there and a lot umm other Lajna go too. And I love living around Ahmadis..

When speaking about location, all participants also noted their parent's immigration history to Canada directly impacted who they were as Canadians and Ahmadi Muslims today. They expressed gratitude towards their parent's hard work which enabled them to have the lives they currently enjoyed. They all worked harder, had a sense of responsibility, were motivated to be more successful and kept an open mind.

One factor which was very different for one participant was media and fashion. One participant noted this had a huge impact on her identity formation as she was easily influenced. This factor stood out as none of the other participants mentioned media or fashion as having any influence.

Ameera: And then also media. 100 percent the media.... as soon as I became aware of the shows people were watching or what was the trend, in terms of fashion. Fashion was always something that I loved... umm and I guess it also comes back to the fact that like I was restricted in fashion clothing or something and in high school I wore a uniform so that shaped my identity

The media and fashion did indeed create conflicts for her because the messaged she received were very different from those of the Ahmadi community. She had trouble living up to the expectation of the Ahmadi community and her Canadian peers. She often found herself living according to her peers rather than her Islamic values. She was heavily influenced by what the media depicted as a Canadian woman and also the fashion industry.

\section{Chapter 7: Discussion}

This study contributes to the literature on Muslim identity in several ways. The young Ahmadi Muslim women had a very specific sense of understanding of their Ahmadi Muslim and Canadian identities. This was especially true for their Ahmadi identity, strongly expressed through their affiliation with the Jama 'at, at the local level and beyond. Research on Muslim 
identity often finds differences in the way Islam is interpreted in the West and this research was no different. However, one new idea that emerged was from the Ahmadi identity as that had not been explored before. Participants reported a difference in what it meant to be Muslim and what it meant to be Ahmadi; not because the values and teachings are different. Rather, they attributed different levels of religiosity for both and the way they practiced it. Being Muslim was an individual level identity where it was about praying, wearing the Hijab and reading Quran etc. Whereas being Ahmadi meant having a sense of community, being united, having a sense of sisterhood and that support system. Being Ahmadi was more of a collective identity where being Muslim meant following the basic teachings of Islam.

Interestingly, the Muslim identity is consistent with previous literature as other studies have found Muslims to attribute private practices as an important part of being Muslim. However, the differences in private practices did not occur because of the different sect which is the case in this situation. Further, Ahmadi women were able to use the Jama 'at as a way to balance the identities and stay away from things like dating, drinking and going out late. The Jama 'at had a major influence on the women's identity development and was also a big part of being an Ahmadi. The women recognized that it was indeed the Jama 'at and its people that allowed them to balance their identities without having internal conflicts. The Jama'at provided a good sense of belonging and made them feel welcomed. The Jama 'at also allowed them to make new friends and attend educational events. This is interesting because some argue that Islam is backward and keeps women away from mainstream society but here the participants expressed the Jama 'at being the very reason they were able to live by both value systems. Even the women who wore the Hijab were still strong in their Canadian identity and were working or in school. The Hijab had not interfered with their Canadian lifestyle. The Jama 'at allowed the 
women to feel comfortable with who they were because they knew no matter what happened or how they were treated by other Canadians, they would always have the Jama 'at to accept them. The Jama 'at would always be there as a support system, and a place to express their Muslim and Ahmadi identity. The Jama'at and attachment to the religious community was a major factor in Ahmadi identity and is different than other Muslims and the previous literature. There is no doubt that many Muslims have a strong attachment to their religious communities and have strong community ties. However, for Muslims born in Canada, their sense of religion has been found to be a little different. As Beyer et al (2013) found that from her 58 Muslim participants, "their religious identities were not shaped or nurtured primarily or all that directly by their religious communities....." (p.120). Ahmadi Muslim women in this study gave precedence to their community rather than having private, individualized religious lives. Moreover, the most intriguing aspect of the influence of the Jama 'at were the female influences. All participants mentioned a strong influence of female figures right from their childhood up until now. The influences on dressing, veiling, finding careers and participation in the Jama 'at was not by Imams or fathers. Rather, it was the mothers, sisters and teachers in the Jama'at which heavily influenced their identities. These women grew up watching their mothers and sisters and other women who had positions of authority within the Jama'at. They were able to learn and shape their identities based on their teachings. As mentioned earlier, this is contradictory to the depiction of Islam as being oppressive and male dominant. Very rarely does anyone associate strong female leadership with Islam. These women had guidance from females who were well established both religiously and had careers. In fact, many of these women would not have been able to deal with the clash in values without these women. This is a unique finding which adds to the literature on Muslim women. It shows the different roles that Ahmadi women play within 
their community which empowers younger women and keeps them connected to their religious roots. Ahmadi women play a significant role in raising their daughters and spend endless time trying to provide guidance for these women.

Being Canadian was also consistent with previous research in terms of having diversity, acceptance of multiculturalism and freedom (Beyer et al, 2013; Tiflati, 2017). Similarly, perceived Canadian identity for the women and how other Canadians actually viewed them was also consistent with previous literature (Yousif, 2010). Almost all participants viewed themselves as Canadians and had a strong sense of being Canadian. They participated in Canadian 'activities' and were just like many of their Canadian peers in terms of working and studying. However, many experiences revealed that professors and peers did not view them as Canadian. Even participants who were very enthusiastic about 'Canadian' activities such as hockey, were not treated the same within their hockey culture. They were clearly told that hockey was a 'Canadian sport', which meant being white. This was especially evident for visible Muslims who wore the Hijab. They were often only seen as 'Muslim' and not Canadian. However, even when participants were told or treated different and not 'Canadian', they were not affected negatively. Their sense of being Canadian was strong and those experiences did not change that. This finding reinforced the ideology which still exists within Canada on who defines a 'true Canadian'. Although the women themselves felt like Canadians, they were given messages, often hidden about the reality of a 'white Canada', which hides itself in a multicultural and diverse society. This is not to say that all Canadians are not accepting of minorities and people of colour. But the discourse around a real Canadian identity often emerges in people's actions and attitudes towards minorities. This is especially evident in the subtle discrimination which the participants brought up. This study reinforces the sense of otherness which still exists 
within Canada, even if it is subtle. Nonetheless, even the participants who had faced discrimination, their outlook and views of being Canadian were very positive. They recognized that there will always be some people who will not accept you, but they said those experiences of discrimination were 'not representative' of the real Canadian values. The participants were very comfortable with how people saw them both within the Ahmadi Muslim community and the larger Canadian society. In fact, many women felt very respected by peers, colleagues and professors and even the participants who were aware that they were being treated differently, it had a positive effect on them because felt they were being treated with respect. This was also true for a participant who described a male professor that normally shook everyone's hand at the end of the year. However, upon seeing a student with a Hijab, he automatically assumed she did not shake hands and adjusted his farewell greeting. Now, although he treated her differently than the rest of the students, the student perceived this experience as positive and appreciated the actions of a white, male professor. Nonetheless, these experiences demonstrated that the way the participants viewed themselves in terms of Canadian identity, and how others viewed them were different. The same goes with being Ahmadi Muslim because even the two participants that were not that religious or involved, their peers in the Canadian society thought they were very religious because they prayed five times, wore the Hijab and were modest.

Additionally, this study showed a unique relationship that minority groups such as Ahmadis have with both Canadians and Muslim majorities. The women in this study revealed they had instances of discrimination by other Muslims which shows that Muslims are not a homogenous group and they have internal issues. This finding can help other Canadians understand the difficulties which religious minorities face even within their own communities. They must battle not only the negative attention from outside the Muslim community, but also 
within. This further marginalizes these women who are already trying to find a balance between different cultures. One important finding in terms of being Ahmadi Muslim was that even though Ahmadis are discriminated by other Muslims and considered Muslims; most participants identified as Muslim before Ahmadi. This demonstrates a complicated relationship between Ahmadi women and other Muslims women because the women in this study were strongly recognized as Muslim women.

The major findings indicate a unique understanding of identities for these young women who appreciate both cultures and feel like they belong. Identity thus manifests itself in fascinating ways as internal and external, changing and mixing of two cultures which are different but still share some similarities. This study helped provide a perspective on Ahmadi Muslim identity and how these young women deal with issues of identity formation, differences in values and discrimination. The sample size was small, and the results of this study cannot be generalized, but it still provided strategies on how Ahmadi Muslim women conceptualize their identities within a predominantly white society. They provide insight into how they manage to form their identities by including pieces of both cultures and having a strong attachment to their Jama 'at, which was a key factor in their identity negotiations. It shows how hybridized identities manifest themselves even with women born and raised in Canada because of their religious beliefs. Further, this study reinforces Stets and Burkes (2000) work within social and identity theory as it demonstrates the overlap between group identities and role identities. Ahmadi Muslims spoke about their identities in different roles such as being a student, a mentor and associated with group memberships such as Ahmadi and Pakistani. This is especially true for the participants in this study who are part of a specific social group which is the Ahmadi Muslim community. In this scenario, the in-group are the Ahmadi women and their Jama 'at while the 
out-group is the Canadian society. They recognize the people who are members of the out-group and realize the differences, but do not use a negative perception of them to enhance self-esteem. This is because although they are part of a social group, their personal identities consist of being Canadian as well. In fact, these young women merge both cultures together to form a unique identity.

The findings in this study cannot be generalized but still raise implications for both theory and practice. When speaking of Muslims in the literature, scholars need to differentiate between different groups because their experiences and views can be different. Identity theorists also need to keep in mind the complexity of identities when trying to define and analyze through one single approach. Especially when examining the identities of young women who belong to more than one culture. Further, there are recommendations for different populations who can help these young women better navigate and form their identities. Many young women stated having strong ties to the Jama 'at helped them balance the clash in values and stay away from "un Islamic" activities. Therefore, the Ahmadiyya Muslim Jama 'at can do more for its young members to keep that strong bond and sense of community. They can continue to foster a positive environment which encourages participation in religious activities. Also, some women mentioned the lack of discussion on certain topics such as dating, and relationships, and being judged by community members; which was attributed to culture (Pakistani specifically) and not religion. Thus, a recommendation for the Ahmadiyya Jama 'at can be to continue to create a more open and accepting space for young women to come and ask questions without being judged on specific topics such as dating, relationships etc. They can further try to differentiate between religion and culture so that young women who are not as religious can still feel welcomed and accepted into the community and participate in their events without having to 
adopt cultural values. Further, for Ahmadi parents who had an open relationship with the young women and were good role models, they were better able to foster healthy and balanced identities. Thus, Ahmadi mothers can especially play a big role in helping shape the identities of young Ahmadi women. Lastly, professionals within educational institutions should be culturally competent to understand how they should approach people who have differences in values. As Muslim women mentioned they had instances where professors assumed certain aspects of their identity and although it was not perceived negatively for the women in this study, it is possible others may be offended. By these groups working together, Ahmadi Muslim women can be supported in forming strong and healthy identities that help them navigate their way through the Canadian society.

\section{Chapter 8: Conclusion}

This is one of the first studies which addresses identity formation of Ahmadi Muslim women in Canada, specifically Ontario. This study contributed to previous literature on Muslim identity as it introduced a new minority to the literature. The women described various facets of their identity such as being a Muslim, Ahmadi and Canadian at the same time and many influences on identity were revealed such as family, location and the Jama 'at. Being Canadian and Ahmadi Muslim were both identities which were important aspect of their lives. This study showed low levels of discrimination, but a lot of subtle discrimination was present and a good sense of belonging for majority of the women. This study shows positive relations between minority groups and Canadians which demonstrates a better sense of multiculturalism in Ontario. However, this study was small, and limited to the GTA and thus findings cannot be generalized. Subsequently, a few implications for future research are noted. 
There needs to be more research conducted with this population to understand their identity formation. Further, a large-scale study would be very beneficial as the Ahmadi Muslim community is established in different parts of Canada, with a strong link to community. It would be valuable to study Ahmadis that live in remote areas and find the impact which location has on their Canadian identity. Another interesting research would be to see the differences between the experiences of Ahmadi men and women as the experiences can be very different. This is especially true because women have displayed stronger religious identities throughout the literature. 


\section{References}

Ahmad, A. (2017). Canadian values and the Muslim world. International Journal, 72(2), 255 268. doi:10.1177/0020702017710920

Ahmad, M. G. (2007). A Misconception Removed (2nd ed.). Retrieved from https://www.alislam.org/library/books/A-Misconception-Removed.pdf

Ahmad, M. G. (n.d.). Ruhani Khaza'in, Vol. 3: Izala-i-Auham. Retrieved from https://www.alislam.org/library/browse/volume/Ruhani_Khazain/book/Izala_Auham/?1= English\#page/113/mode/1up

Ahmed-Ghosh, H. (2004). Portraits of believers: Ahmadi women performing faith in the diaspora. Journal of International Women's Studies, 6(1), 73.

Ahmed-Ghosh, Huma (2006). Ahmadi Women Reconciling Faith with Vulnerable Reality through Education. Journal of International Women's Studies, 8(1), 36-51

Aziz, N. (Ed.). (2015). The relevance of Islamic identity in Canada: Culture, politics, and self. Toronto: Mawenzi House publishers Ltd.

Bakht, N. (2008). Belonging and banishment: Being Muslim in Canada. Toronto: TSAR.

Bectovic, S. (2011). Studying Muslims and constructing Islamic identity. Ethnic and Racial Studies, 34(7), 1120-1133. doi:10.1080/01419870.2010.528782

Berger, R. (2015). Now I see it, now I don't: Researcher's position and reflexivity in qualitative research. Qualitative Research, 15(2), 219-234. doi: 10.1177/1468794112468475

Berk, E. (2012). Emotional and Social Development in Adolescence. In Infants, Children, and Adolescents (7th ed., pp. 600-601). Boston. 
Beyer, P., \& Ramji, R. (Eds.). (2013). Growing up Canadian: Muslims, Hindus, Buddhists. Montréal, Québec: McGill-Queen's University Press.

Boeije, H. (2010). Analysis in qualitative research. London. Sage

Bosma, H. A., Graafsma, T. G., Grotevant, H. D., \& De Levita, D. J. (Eds.). (1994). Identity and development: An interdisciplinary approach. Thousand Oaks, CA: Sage Publications.

Bullock, K. (2014). Towards a Framework for Investigating Muslim Women and Political Engagement in Canada. In J. Zine (Ed.), Islam in the Hinterlands: Muslim Cultural Politics in Canada. Vancouver: UBC Press.

Burke, P. J., \& Stets, J. E. (2009). Identity theory. New York: Oxford University Press.

Cote, J. E. (1996). Identity: A multi-dimensional analysis. In G. R. Adams, R. Montemayor, \& T. P. Gullotta (Eds.), Psychosocial development during adolescence. Progress in developmental contextualism (Advances in Adolescent Development, Vol. 8, pp. 130180). Thousand Oaks, CA: Sage.

Creswell, J. W. (2014) Research design. Thousand Oaks: Sage. Ch.1

De Tona, C (2006) But what is interesting is the story of why and how migration happened. Forum: Qualitative Social Research 7: Article 13. Available at: http://www.qualitativeresearch.net/fqs-texte/3-06/06-3-13-e.htm (accessed 26 July 2007). Google Scholar

Eid, P. (2015). Balancing agency, gender and race: How do Muslim female teenagers in Quebec negotiate the social meanings embedded in the hijab? Ethnic and Racial Studies, 38(11), 1902-1917. doi:10.1080/01419870.2015.1005645 
Environics Institute, "Survey of Muslims in Canada j National Survey in Canada j Public Opinion Canada j The Environics Institute," https://www.environicsinstitute.org/projects/project-details/survey-of-muslims-in-canada2016 (accessed 28 March 2017).

Erikson, E. (1980). In The Harvard guide to modern psychiatry. In Nicholi, A. Cambridge: The Belknap Press of Harvard University Press.

Esposito, J. L., \& Kalin, I. (Eds.). (2011). Islamophobia: The challenge of pluralism in the 21st century. New York: Oxford University Press.

Gay, P. D., Evans, J., \& Redman, P. (Eds.). (2000). identity: a reader. London: Sage Publication Ltd.

Giorgi, A. (2009). The descriptive phenological method in psychology: A modified Husserlian approach. Pittsburgh, PA: Duquesne University Press.

Hamdani, D. (2015). Canadian Muslims: A Statistical Review. Retrieved from http://muslimlink.ca/pdf/Canadian-Muslims-A-Statistical-Review-Final.pdf

Hamdon, E. L. (2010). Islamophobia and the question of Muslim identity: The politics of difference and solidarity. Halifax: Fernwood Publishing.

Hogg, M. A., \& D, Abrams. (1988) Social identifications. A social psychology of intergroup relations and group processes. London: Routledge.

Humanity First. (2018). Who We Are? Retrieved from https://www.humanityfirstcanada.ca/

Hussain, A. (2004). Muslims in Canada: Opportunities and challenges. Studies in Religion, 33(34), 359-379. doi:10.1177/000842980403300305 
Kacen, L, Chaitin, J (2006). The times are a changing: understanding qualitative research in ambiguous, conflictual and changing contexts. Qualitative Report 11: 209-228. Google Scholar

Kassam, A. (2007). Locating identity and gender construction in a post 9/11 world: The case of the hijabi girl. Intercultural Education, 18(4), 355-359. 10.1080/14675980701605303

Khalifa of Islam. (2018). Retrieved from https://www.khalifaofislam.com/about-his-holiness

Khan, S. (1998). Muslim women: Negotiations in the third space. Signs, 23(2), 463-494. doi:10.1086/495259

Kroger, J. (2007). Identity development: Adolescence through adulthood (2nd ed.). Thousand Oaks, CA: Sage Publications.

Litchmore R. V., Safdar, S. (2014). Perceptions of discrimination as a marker of integration among Muslim Canadian youth: The role of religiosity and ethnic identity. Journal of International Migration and Integration, 16, 187-204. doi: 10.1007/s12134-014-0337-5

Litchmore, R. V. H., \& Safdar, S. (2016). Meanings of the hijab: Views of Canadian Muslim women. Asian Journal of Social Psychology, 19(3), 198-208. 10.1111/ajsp.12141

Malik, L. K. (2013). The Ahmadiyya Muslim Community in Canada - The Review of Religions The Review of Religions. Retrieved from http://www.reviewofreligions.org/8582/theahmadiyya-muslim-community-in-canada/

Mendelsohn, M. (2007). Measuring National Identity and Patterns of Attachment: Quebec and Nationalist Mobilization. Nationalism and Ethnic Politics 8.3: 72-94.

Meshal, A., R (2003). Banners of faith and identities in construct: the Hijab in Canada. In Alvi, 
McDonough \& Hoodfar (Eds). The Muslim veil in North America issues and debates (72-105). Toronto: Women's Press

Moghissi, H., Rahnema, S., \& Goodman, M. J. (2011). Diaspora by design: Muslim immigrants in Canada and beyond. Toronto: Univ. of Toronto Press.

Mohammadi, F. (2018). Becoming a hijabi now? Identity Performances of Muslim women in Canada. Religious Studies and Theology, 37(1), 5-21. doi:10.1558/rsth.32257

Moulin, D. (2015). Religious identity choices in English secondary schools. British Educational Research Journal, 41(3), 489-504. doi:10.1002/berj.3151

Moustakas, C. (1994). Phenomenological research methods. Thousands Oaks, CA: Sage.

Nagra, B. (2011). 'Our faith was also hijacked by those people': Reclaiming Muslim identity in Canada in a post-9/11 era. Journal of Ethnic and Migration Studies, 37(3), 425-441. doi:10.1080/1369183X.2011.526781

Nagra, B., \& Maurutto, P. (2016). Crossing borders and managing racialized identities: Experiences of security and surveillance among young Canadian Muslims. Canadian Journal of Sociology (Online), 41(2), 165.

Pakistan mosque attacks in Lahore kill scores. BBC NEWS. (2010, May 29) BBC NEWS. Retrieved from https://www.bbc.com/news/10181380

Rahman, A. (1996). Chapter 7: The Worldwide Ahmadiyya Movement. In Pathway to Paradise. Women's' Auxiliary, Ahmadiyya Movement In Islam, Inc. U. S. A.

Riessman, C. K. (2009, March 2nd). Considering grounded theory: Categories, cases, and control: 1. Symbolic Interaction, 32(4), 390. 
Rosella, L. (2017). Mississauga dad who killed teenage daughter dies in prison. THE HAMILTON SPECTATOR. Retrieved from https://www.thespec.com/newsstory/7167867-mississauga-dad-who-killed-teenage-daughter-dies-in-prison/

Saldaña, J. (2016). The coding manual for qualitative researchers (3rd ed.). Thousand Oaks, CA: Sage

Tiflati, H. (2017). Muslim youth between Quebecness and Canadianness: Religiosity, identity, citizenship, and belonging. Canadian Ethnic Studies, 49(1), 1-17. 10.1353/ces.2017.0000

Statistics Canada Government of Canada, “Canadian Identity, 2013," 1 October 2015, http:// www.statcan.gc.ca/pub/89-652-x/89-652-x2015005-eng.htm

Stets, J. E., \& Burke, P. J. (2000). Identity theory and social identity theory. Social Psychology Quarterly, 63(3), 224-237. doi: 10.2307/2695870

Tiflati, H. (2017). Muslim youth between Quebecness and Canadianness: Religiosity, identity, citizenship, and belonging. Canadian Ethnic Studies, 49(1), 1-17. 10.1353/ces.2017.0000

Waugh, E., Abu-Laban, B., Qureshi, R., (eds). (1983). The Muslim Community in North America. Edmonton: The University of Alberta Press.

Wilkins-Laflamme, S. (2018). Islamophobia in Canada: Measuring the realities of negative attitudes toward Muslims and religious discrimination: Islamophobia in Canada. Canadian Review of Sociology/Revue Canadienne De Sociologie, 55(1), 86-110. doi:10.1111/cars. 12180

Wong, J. P., Macpherson, F., Vahabi, M., \& Li, A. (2017). Understanding the sexuality and sexual health of Muslim young people in Canada and other western countries: A scoping 
review of research literature. The Canadian Journal of Human Sexuality, 26(1), 48-59. doi:10.3138/cjhs.261-C1

Yousif, A. F. (2008). Muslims in Canada: A question of identity (2nd ed.). New York: Legas.

Zine, J. (2001). Muslim youth in Canadian schools: education and the politics of religious identity. Anthropology \& Education Quarterly. doi:10.1525/aeq.2001.32.4.399.

Zine, J. (2006). Unveiled sentiments: Gendered islamophobia and experiences of veiling among Muslim girls in a Canadian Islamic school. Equity \& Excellence in Education, 39(3), 239-252. 10.1080/10665680600788503

Zine, J. (Ed.). (2012). ISLAM IN THE HINTERLANDS: MUSLIM CULTURAL POLITIC IN CANADA. Vancouver: UBC Press.

Zirvi, K. (2010). Welcome to Ahmadiyyat, the true Islam. Islam International. 


\section{Glossary}

(aa): May Allah strengthen him with his help- used for the current serving Khalifa

Auda: Position/ role

Ahmadiyyat/Ahmadiyya Muslim Jama 'at: The name of the sect of Islam which believes in the Promised Messiah

Ahmadi Muslims: The followers or believers who practice Ahmadiyyat and believe in the Promised Messiah

(As): A symbol that follows the names of most other Prophets and Messengers of God meaning ('alai hissalam'), which translates to on whom be peace.

Hijab: A head covering worn by Muslim women to cover their hair and bosom

Imam Mahdi: The Guided Leader.

Jalsa: annual religious convention which brings together people from the Ahmadi community enhance spirituality

Jama 'at : Community, Organization

Khalifa: Vicegerent Successor; caliph.

Khilafat: Succession or system of khalifas

Lajna: An auxiliary organization of Ahmadi ladies above the age of 15 years

Nabi: Prophet

Namaz: Islamic Prayer

Nasirat: An auxiliary organization of Ahmadi girls between the ages of 7 and 15 years

Promised Messiah: The metaphorical second coming of Jesus ${ }^{\text {as }}$ of Nazareth and the divine guide, whose advent was foretold by the Prophet of Islam, Muhammad ${ }^{\text {saw }}$

Purdah: Veiling; Men and women sitting separately, dressing modestly, lowering your gaze etc (Ra): May Allah have mercy on him

Rasul: Messenger.

(Saw): A symbol that follows the name Muhammad and his titles - the Holy Prophet or the Founder of Islam - for (sallallahu 'alaihi wa sallam) which means May peace and blessings of Allah be upon him.

Veiling: in this study it referred to 'covering of the head or body' with a hijab and or burqa/coat. This did not include a niqab. 